Review

\title{
Wind Turbine Condition Monitoring: State-of-the-Art Review, New Trends, and Future Challenges
}

Pierre Tchakoua ${ }^{1,2, *}$, René Wamkeue ${ }^{1,2}$, Mohand Ouhrouche ${ }^{1}$, Fouad Slaoui-Hasnaoui ${ }^{2}$, Tommy Andy Tameghe ${ }^{1,2}$ and Gabriel Ekemb ${ }^{1,2}$

1 Department of Applied Sciences, University of Quebec, Chicoutimi, QC G7H 2B1, Canada; E-Mails: rene.wamkeue@uqat.ca (R.W.); mohand_ouhrouche@uqac.ca (M.O.); tattameghe@uqac.ca (T.A.T.); gabriel.ekemb@uqat.ca (G.E.)

2 School of Engineering, University of Quebec, Rouyn-Noranda, QC J9X 5E4, Canada; E-Mail: fouad.slaoui-hasnaoui@uqat.ca

* Author to whom correspondence should be addressed; E-Mail: pierre.tchakoua-takoutsing@uqat.ca; Tel.: +1-819-762-0971 (ext. 4382); Fax: +1-819-797-4727.

Received: 14 February 2014; in revised form: 23 March 2014 / Accepted: 24 March 2014 / Published: 22 April 2014

\begin{abstract}
As the demand for wind energy continues to grow at exponential rates, reducing operation and maintenance $(\mathrm{OM})$ costs and improving reliability have become top priorities in wind turbine (WT) maintenance strategies. In addition to the development of more highly evolved WT designs intended to improve availability, the application of reliable and cost-effective condition-monitoring (CM) techniques offers an efficient approach to achieve this goal. This paper provides a general review and classification of wind turbine condition monitoring (WTCM) methods and techniques with a focus on trends and future challenges. After highlighting the relevant $\mathrm{CM}$, diagnosis, and maintenance analysis, this work outlines the relationship between these concepts and related theories, and examines new trends and future challenges in the WTCM industry. Interesting insights from this research are used to point out strengths and weaknesses in today's WTCM industry and define research priorities needed for the industry to meet the challenges in wind industry technological evolution and market growth.
\end{abstract}

Keywords: wind turbines (WTs); condition monitoring; fault detection; destructive tests; non-destructive tests; subsystem monitoring techniques; overall system monitoring techniques; state of the art; new trends; future challenges 


\section{Introduction}

Energy conversion and efficiency improvement have become a worldwide priority to secure an energy supply and address the challenges of climate change, greenhouse gas emission reduction, biodiversity protection, and renewable technology development. In 2011, renewable sources accounted for nearly $50 \%$ of the estimated globally added electric capacity evaluated at $208 \mathrm{GW}$ [1]. Among all renewable energy sources, wind energy is the fastest-growing sector in terms of installed capacity. As shown in Figure 1, the cumulative installed wind power capacity reached $283 \mathrm{GW}$ in 2011, which represents nearly $3 \%$ of global electricity production. Furthermore, the contribution of wind power to the world total generation capacity is expected to reach $8 \%$ by 2018 [1-3].

Figure 1. Wind energy world market forecast for 2013-2017 [1]. Reprinted/Reproduced with permission from [1]. Copyright 2013, Global Wind Energy Council (GWEC).

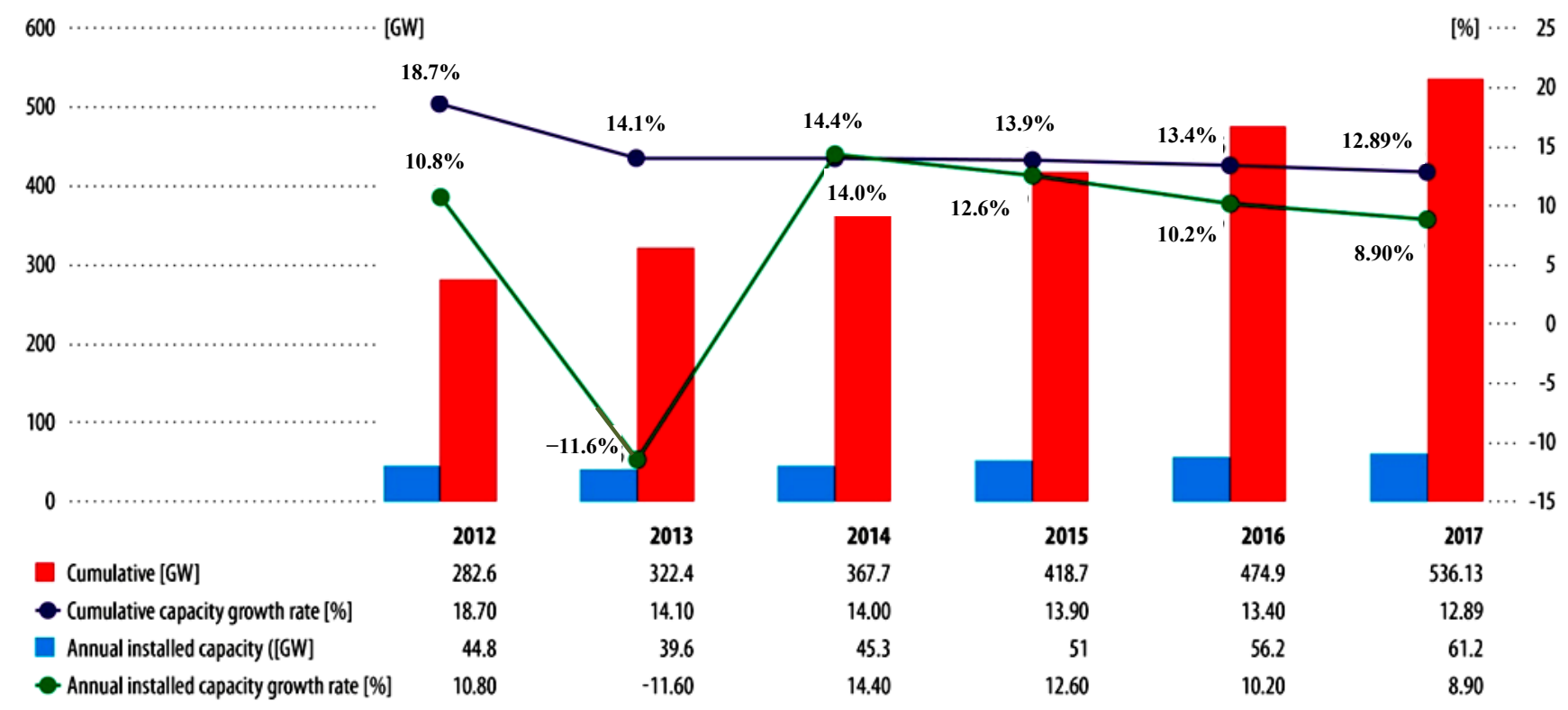

Wind turbines (WTs) are unmanned, remote power plants. Unlike conventional power stations, WTs are exposed to highly variable and harsh weather conditions, including calm to severe winds, tropical heat, lightning, arctic cold, hail, and snow. Due to these external variations, WTs undergo constantly changing loads, which result in highly variable operational conditions that lead to intense mechanical stress [4]. Consequently, the operational unavailability of WTs reaches $3 \%$ of the lifetime of a WT. Moreover, operation and maintenance $(\mathrm{OM})$ costs can account for $10 \%-20 \%$ of the total cost of energy (COE) for a wind project, and this percentage can reach $35 \%$ for a WT at the end of life. A preventive-centered maintenance strategy that avoids machine shutdown can considerably reduce these costs [5-7]. Therefore, WTs require a high degree of maintenance to provide a safe, cost-effective, and reliable power output with acceptable equipment life. The state-of-the-art method for determining the maintenance strategy in the WT industry is reliability-centered maintenance (RCM), which consists of preventive maintenance based on performance and/or parameter monitoring and subsequent actions. In this strategy, condition-monitoring $(\mathrm{CM})$ is used to determine the optimum point between corrective and scheduled maintenance strategies [8-11]. The recurrent and commonly used 
condition-monitoring techniques (CMTs) are: (i) vibration/acoustic-controlled and OM techniques for the turbine; and (ii) optical strain gauges for the blades.

The WTs are typically designed to operate for a period of 20 years [12,13]. As with other mechanical systems, time-based maintenance assumes that the failure behavior of WTs is predictable. Fundamentally, three failure patterns describe the failure characteristics of WT mechanical systems [14].

The bathtub curve shown in Figure 2 illustrates the hypothetical failure rate versus time in a mechanical system [15-18], where $\beta<1$ represents a decreasing failure rate, $\beta=1$ represents a constant failure rate, and $\beta>1$ represents an increasing failure rate.

Figure 2. The "bathtub" curve illustrating the reliability of technical systems.

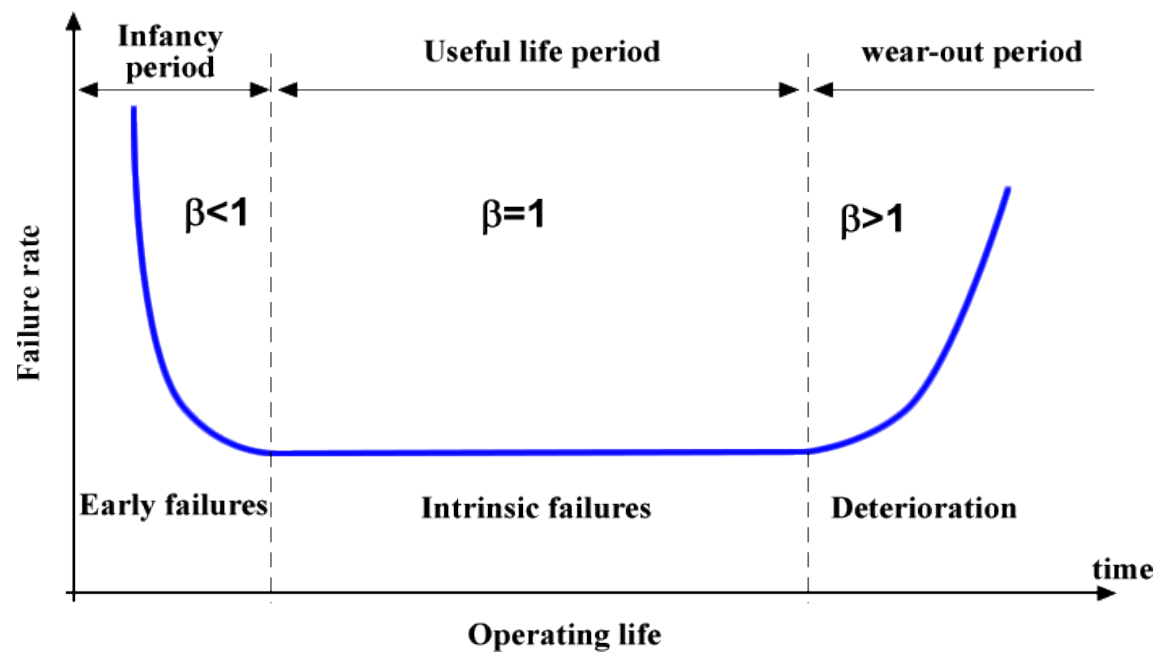

Guo et al. [19] developed a three-parameter Weibull failure rate function for WTs, and their results corroborate the bathtub curve. Echavarria et al. [12] published results of a remarkable 15-year research study on the frequency of failures versus increasing operational age for various WT power ratings (Figure 3).

Figure 3. Number of incidents per wind turbine (WT) per operational year; WTs are categorized by rated power [12]. Reprinted/Reproduced with permission from [12]. Copyright 2008, American Society of Mechanical Engineers.

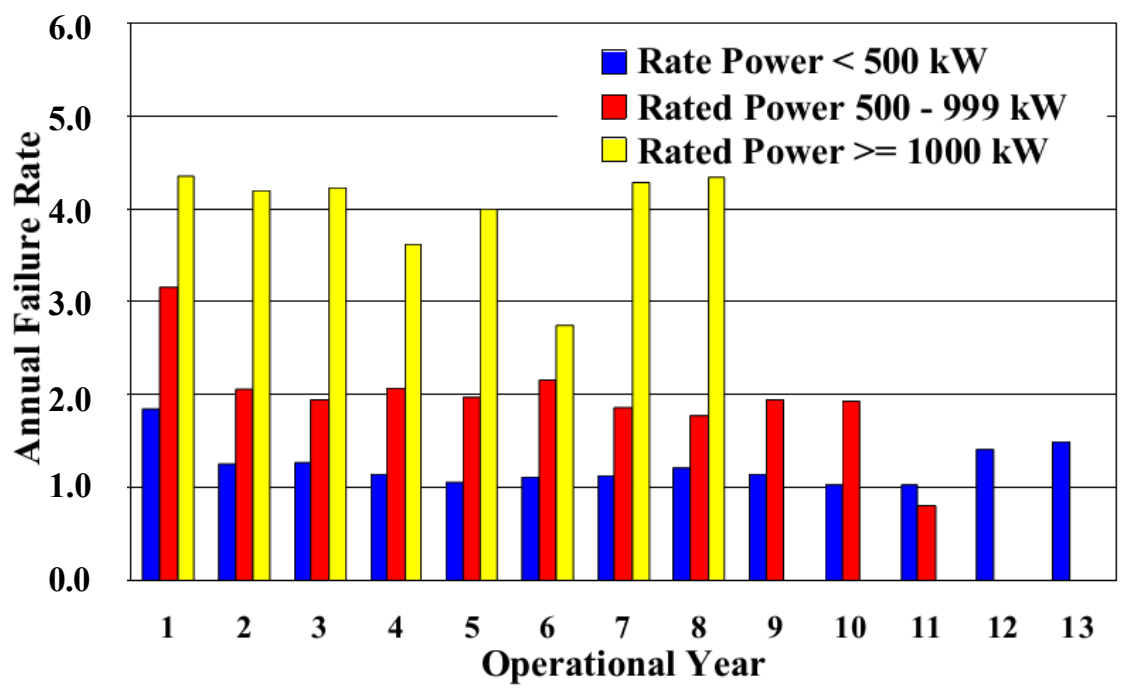


The frequency of failures in WTs also varies with the scale and type. Spinato et al. $[18,20]$ carried out a failure analysis based on onshore WT types, as specified in the Schleswig Holstein Landwirtschaftskammer (LWK) database. The work displayed a general trend of an increasing failure rate with turbine size. Because turbine capacity continues to grow, we can assume that it will be difficult to decrease the initial failure rate. Several research studies considered the distribution of WT failures in the main components [13,20,21]. Haln et al. [13] reported a survey of 1500 WTs over 15 years and found that five component groups, i.e., electrical system, control system, hydraulic system, sensors, and rotor blades, are responsible for $67 \%$ of failures in WTs, as shown by the pie chart in Figure 4.

Figure 4. Share of the main components of the total number of failures [13]. Reprinted/Reproduced with permission from [13]. Copyright 2007, Springer Science + Business Media.

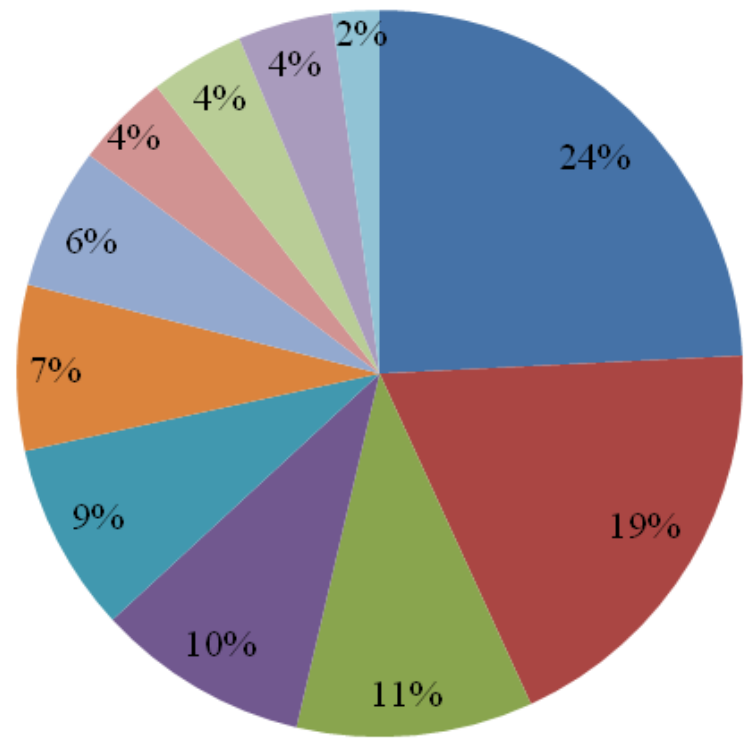

Electrical System
$\square$ Plant control System
@ Sensors
$\square$ Hydraulik System
$\square$ Yaw System
$\square$ Rotor Blades
$\square$ Mechanical Brake
$\square$ Gearbox
$\square$ Structural Parts/Housing
$\square$ Generator
Drive Train

To establish the impact of component failure on WT reliability, research centered on the availability of WTs was presented in [8,22-25]. The results published by Fischer et al. [8] indicated that 75\% of the annual downtime is caused by only $15 \%$ of the failures in WTs. This result corroborates the conclusions of Haln et al. [13], regarding the average failure rate and average downtime per component. The results of this study are also in agreement with the conclusions of Crabtree et al. [24], regarding the comparison of failure rates and downtime for different WT subassemblies based on surveys of European wind-energy conversion systems (WECSs). The chart in Figure 5 summarizes the failure rate and downtime of different WT subassemblies. The reliability and downtime data of the Egmond aan Zee wind farm in Germany also produced similar results, i.e., the gearbox failure rate is low but the downtime and resultant costs are high. As a result, the percentage of electricity production lost due to gearbox downtime is the highest of all subassemblies [24].

A statistical analysis of WT faults demonstrates that their reliability and availability depend on multiple factors, i.e., age, size, weather, wind speed, and subassembly failure rates. However, applying efficient CMTs can greatly increase the reliability of WTs. 
Figure 5. Failure rates and downtime from two large surveys of European WTs over 13 years [13]. Reprinted/Reproduced with permission from [13]. Copyright 2007, Springer Science + Business Media.

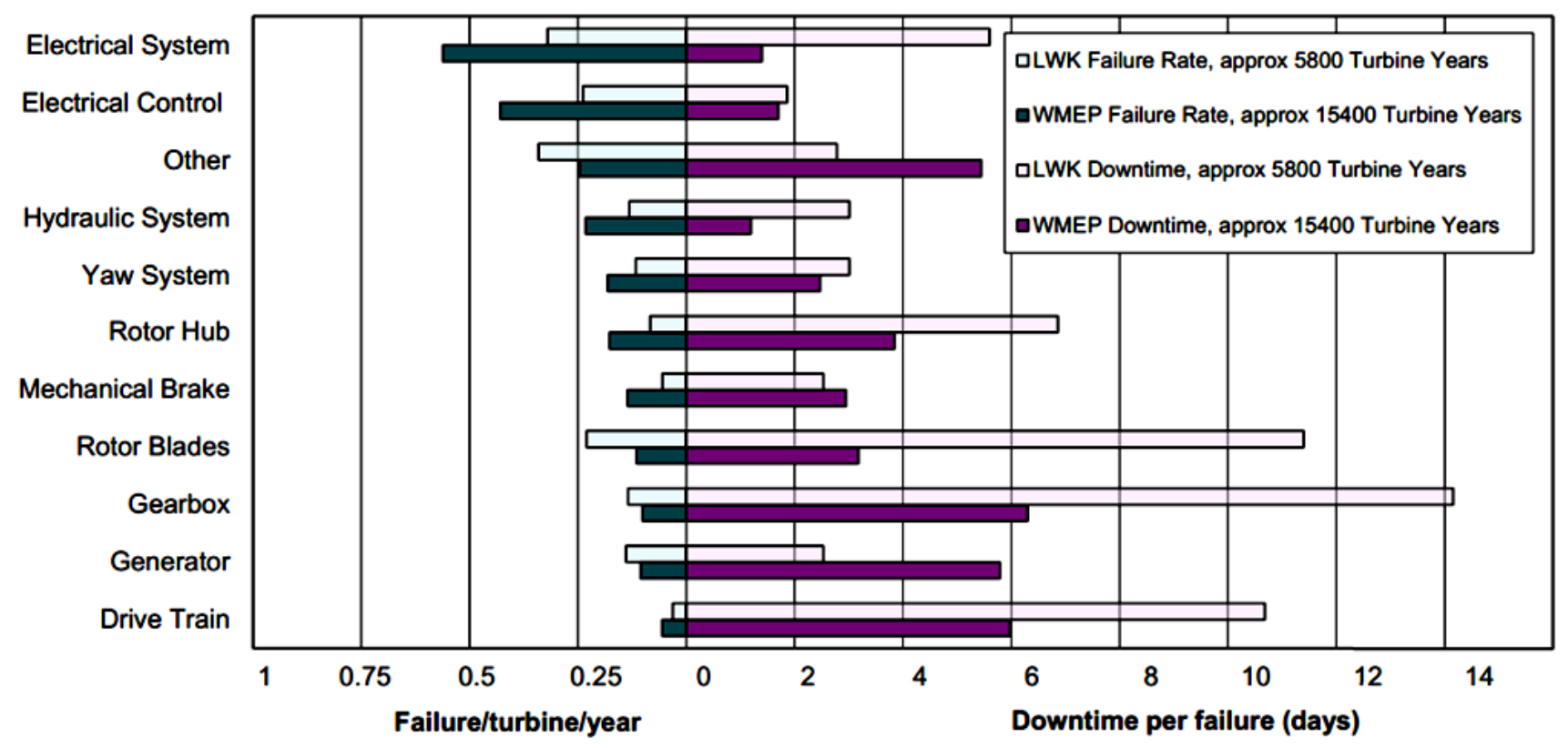

In the literatures, few articles have provided a review of wind turbine condition monitoring (WTCM) and/or fault diagnosis [7,21,26-29]. The goal of this paper is to provide a review of methods and techniques for WTCM with a classification of: (i) intrusive and nonintrusive techniques; and (ii) destructive techniques and non-destructive techniques. This work also focuses on trends and future challenges in the WTCM industry. The paper is organized as follows: Section 2 is dedicated to CM-related concepts and definitions and outlines the relationships among CM, fault diagnosis, and fault prognostic and maintenance strategies; Section 3 presents a review of techniques and methods used in WECSs and CM, subdividing them into subsystem techniques and overall system techniques as well as destructive and non-destructive techniques; Section 4 discusses the new trends and future challenges that will enable the industry to address the WT challenges of the future, including reducing operational costs and improving reliability; finally, Section 5 provides conclusions to the work.

\section{Concepts and Definitions}

\subsection{Maintenance Approaches}

As in most industries, maintenance approaches in the WT industry can be widely classified into three main groups [30,31]:

- Reactive or corrective maintenance (run to failure);

- Preventive maintenance (time-based);

- Predictive maintenance (condition-based).

The COE estimation for a WECS is given by Equation (1) [6,32-35], where ICC is the initial capital investment cost; $F R C$ is the annual fixed charge rate; $E$ is the annual energy production in $\mathrm{kW}$ h; and $O M$ is the annual $O M$ cost: 


$$
C O E=\frac{I C C \cdot F C R+O M}{E}
$$

where $I C C$ and $F R C$ are fixed parameters; and $O M$ is a variable parameter that can affect the $C O E$ during the lifetime of the project. Therefore, the profit from wind energy is highly dependent on the ability to control and reduce this variable cost. The OM cost of equipment will notably depend on the maintenance strategy adopted by the user.

The cost associated with traditional maintenance strategies is presented in Figure 6 [30]. In a preventive maintenance strategy, the prevention cost will be quite high, whereas the repair cost will be low because many potential failures will not occur. In other words, preventive maintenance will considerably reduce the number of failures that occur but will be expensive. In a reactive maintenance strategy, a greater number of faults will occur and will lead to a high cost of repair and low cost of prevention. As shown on the graph, a combination of preventive and reactive maintenance strategies can improve the reliability, availability, and maintainability of WTs while simultaneously reducing the maintenance cost $[4,6,30,36]$.

Figure 6. Costs associated with traditional maintenance strategies.

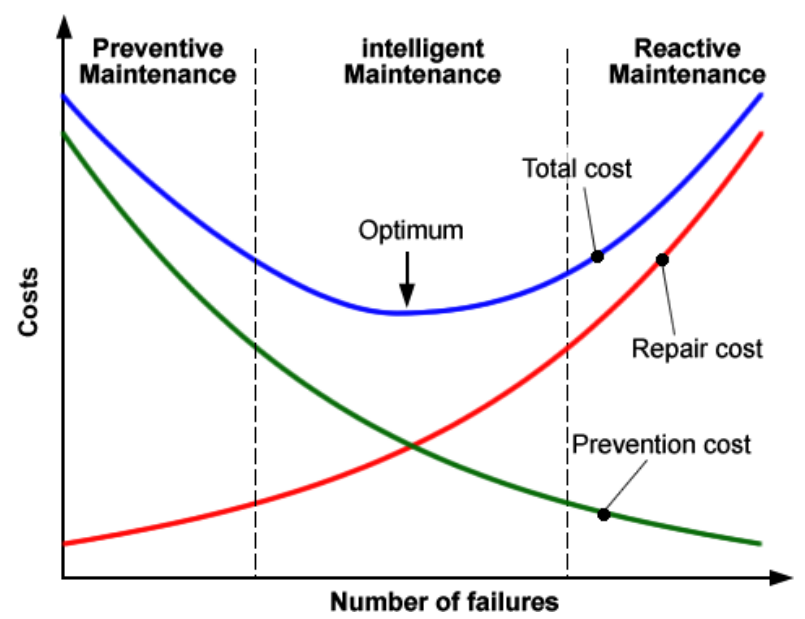

\subsection{CM, Diagnosis, and Maintenance Theories}

Reliability is the ability of a device to perform the required functions under the given conditions for a given time [4,37]. The reliability of a WT is critical for extraction of the maximum energy available from wind. Reliability can be highly improved by the implementation of adequate condition-monitoring systems (CMSs) and fault detection systems (FDSs), and availability is a fundamental measure of reliability. Holen et al. [38] defined availability as the probability that a component or system is capable of functioning at time $\mathrm{t}$, given by Equation (2), where MTTF is the mean time to failure and $M T T R$ is the mean time to recovery:

$$
A=\frac{M T T F}{M T T F+M T T R}
$$

A CMS is a tool used to ensure and measure the reliability of any running system [39]. Wiggelinkhuizen et al. [40] suggested that for WECSs, significant changes are indicative of a developing failure. The continuous component states (i.e., WT health) are evaluated using a collection 
of techniques, i.e., vibration analysis (VA), acoustics, oil analysis (OA), strain measurement (SM), and thermography [27]. Data are sampled at regular time intervals using sensors and measurement systems. Using data processing and analyses, CMSs can determine the states of the key WECS components. By processing the data history, faults can be detected (diagnosis) or predicted (prognostic) and the appropriate maintenance strategy can be chosen.

Maintenance includes any actions appropriate for retaining equipment in or restoring it to a given condition [31]. Maintenance is required to ensure that the components continue to perform the functions for which they were designed. The basic objectives of the maintenance activity are to: (i) deploy the minimum resources required; (ii) ensure system reliability; and (iii) recover from breakdowns [41]. The applied maintenance strategy can be preventive if a predicted failure is avoided or corrective when a detected failure is repaired [42].

A description of and models for CMSs can be found in [27,39,43,44]. This description can be combined with concepts definitions provided in [14,31,45-48], which address maintenance techniques and methods. The diagram relating technical concepts and words used in the domain of WTCM and fault diagnosis emerges from the aforementioned combination. As shown in Figure 7, $\mathrm{CM}$ is performed in three main steps: data acquisition using sensors, signal processing using various data processing techniques, and feature extraction via the retrieval of parameters that will aid in establishing the current status of the monitored equipment. Using both: (i) current information sources; and (ii) information on the system's past status obtained from stored data, the system's present state is obtained via online monitoring such that a fault can be detected or predicted. After a fault is diagnosed, corrective maintenance is carried out. Two approaches to corrective maintenance can be distinguished, i.e., palliative maintenance, which consists of provisional solutions to failures, and curative maintenance for standing solutions to failures. If a fault is predicted, preventive maintenance is carried out before the fault can occur. In this case, four different approaches can be used: time-based or scheduled maintenance, current-state based or conditional maintenance, parameter-projection-based or forecasting maintenance, and status-based or proactive maintenance.

Figure 7. Overview of condition-monitoring (CM) and maintenance processes for WTs.

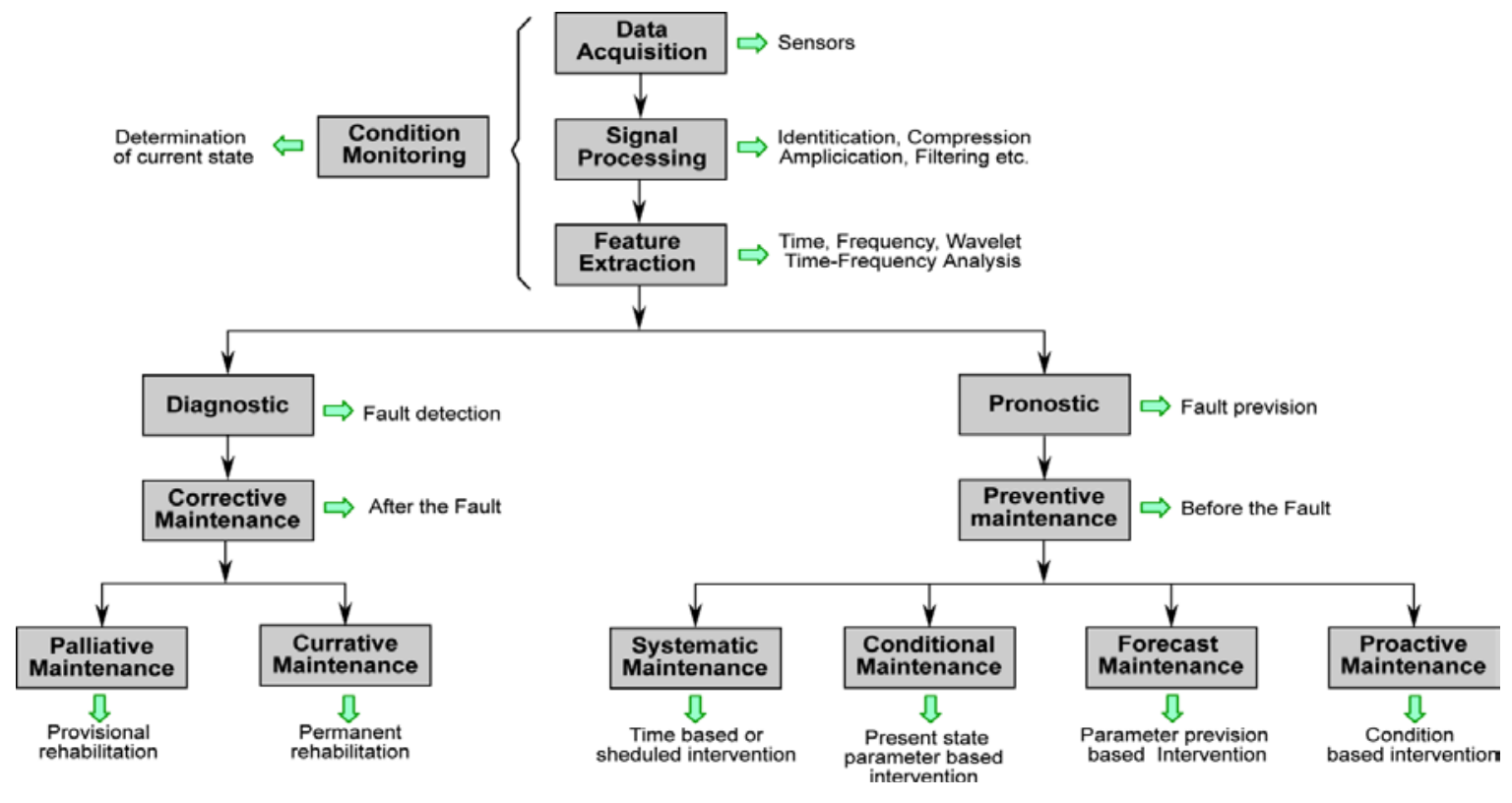




\section{Review of Concepts and Methods for WTCM}

According to the Swedish standard SS-EN 13306 [49], monitoring can be defined as an activity performed either manually or automatically that is intended to observe the actual state of an item. The key function of a successful CMS should be to provide a reliable indication of the presence of a fault within the WECS and to indicate the location and severity of the situation [25]. For this purpose, a CMS is required for early warning sign detection. CM is based on data acquisition and signals processing and can be implemented using various approaches with different levels of technology [46].

A complete CMS is composed of many subsystems, each monitoring a particular component of the wind generator [50]. Due to the considerable level of overlap between functions of different subsystems, certain CM subsystems will monitor many components of the WT. The approach proposed in this review differentiates CMTs applied on WT subsystems from CMTs applied on the overall WT system.

\subsection{WT Subsystems or Intrusive CM Techniques}

The subsystem-level CM of WTs is based on subcomponents related to local parameters [27,28,51] and enables the acquisition of information on specific components and thus the precise localization of eventual failures. The typical main components of a utility-scale WT are presented in Figure 8, and an example of a function model for the monitoring of a WECS based on the subsystem approach is presented in Figure 9.

Figure 8. Typical main components of a utility-scale WT.

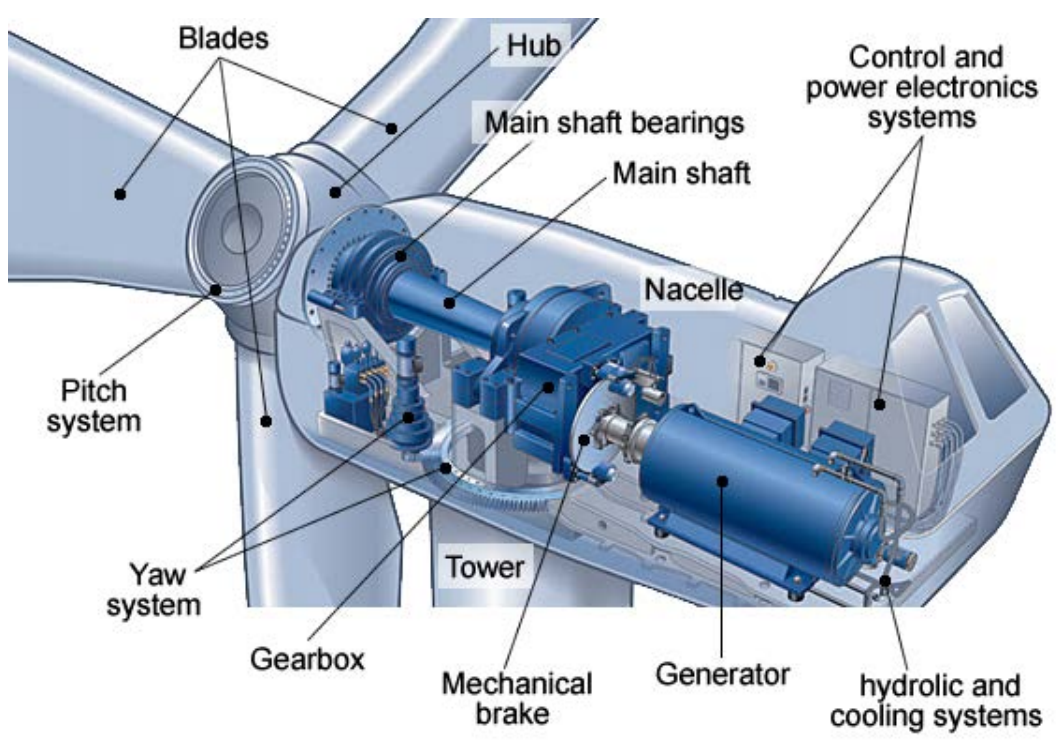

Subsystem CM can be classified into two main subcategories, namely, those based on destructive test (DT) and those based on non-destructive test (NDT) [52].

Subsystem CM based on DT uses:

- VA;

- OA;

- SM; 
- Electrical effects;

- $\quad$ Shock pulse method (SPM);

- Physical condition of materials;

- Self-diagnosis sensors;

- Other techniques.

Subsystem CM based on NDT uses:

- $\quad$ Ultrasonic testing techniques (UTTs);

- Visual inspection (VI);

- Acoustic emission;

- Thermography;

- Performance monitoring;

- Radiographic inspection.

Figure 9. Function model for monitoring of a wind-energy conversion system (WECS) [53]. BCU: boundary controlling unstable; and RMS: root mean square. Reprinted/Reproduced with permission from [53]. Copyright 2008, Blekinge Institute of Technology.

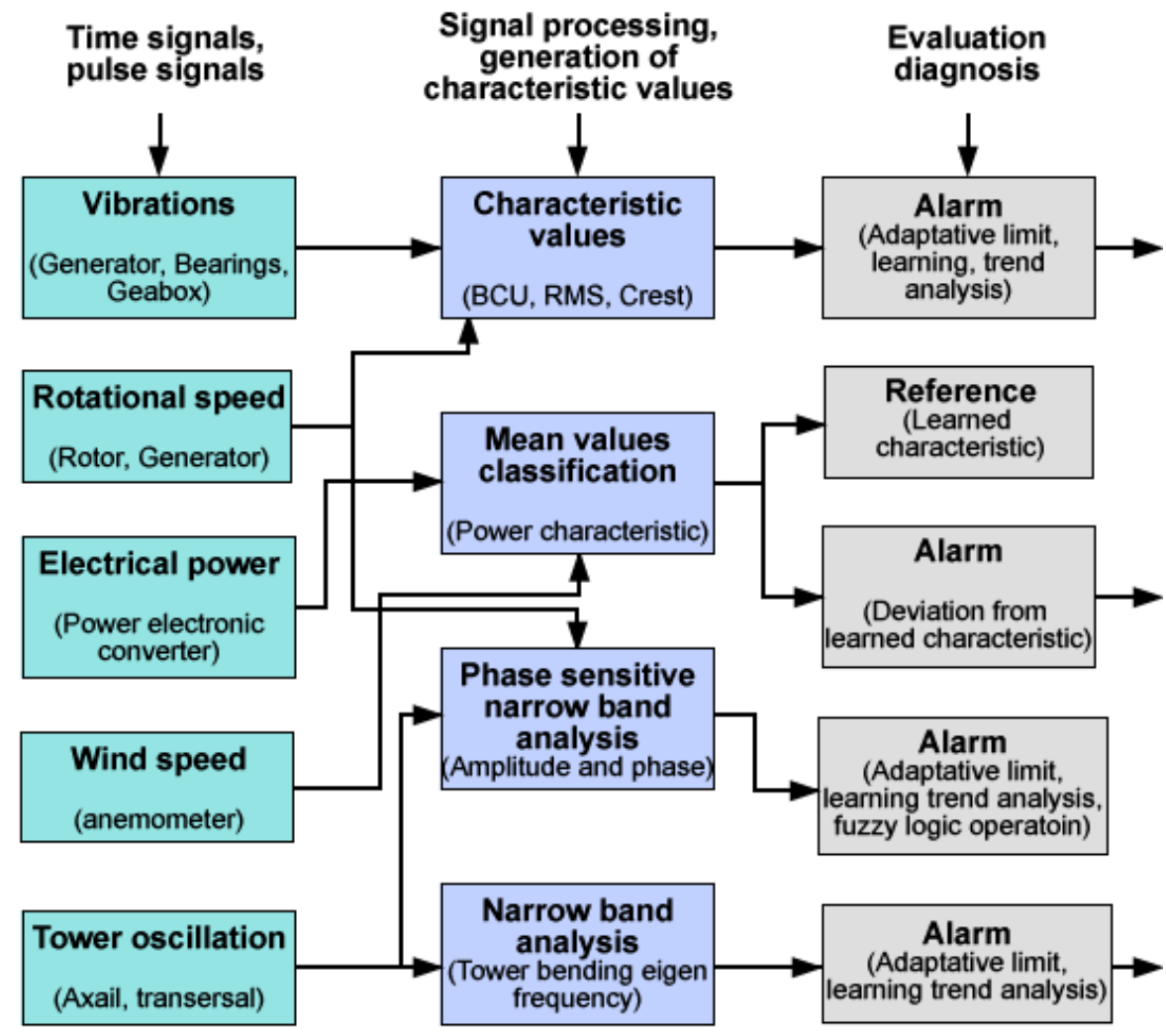

\subsubsection{Subsystem CM Techniques Based on DTs}

As stated in [54], a DT is "a form of mechanical test (primarily destructive) of materials whereby certain specific characteristics of the material can be evaluated quantitatively". DTs are generally realized more easily and yield additional data that are easier to interpret than those from NDTs $[55,56]$. As applied to WECSs, DTs are dynamic or static and can provide useful information related to the material's design considerations, equipment performance, structural health, and useful life. 


\subsubsection{VA}

VA is the most well-known technology for rotating equipment CM. As shown in Figure 10, VA is the most efficient technology for early prediction and detection of failures in mechanical equipment [32]. Applied sensor technology is selected by considering the frequency range and operating conditions [57]. Position transducers, velocity sensors, accelerometers, and spectral emission energy sensors are used for low-, middle-, high-, and very-high-frequency ranges, respectively. Fast Fourier transformation is the signal processing technique commonly used in VA to convert a time-domain signal into a frequency-domain signal [58].

Figure 10. Typical development of a mechanical failure.

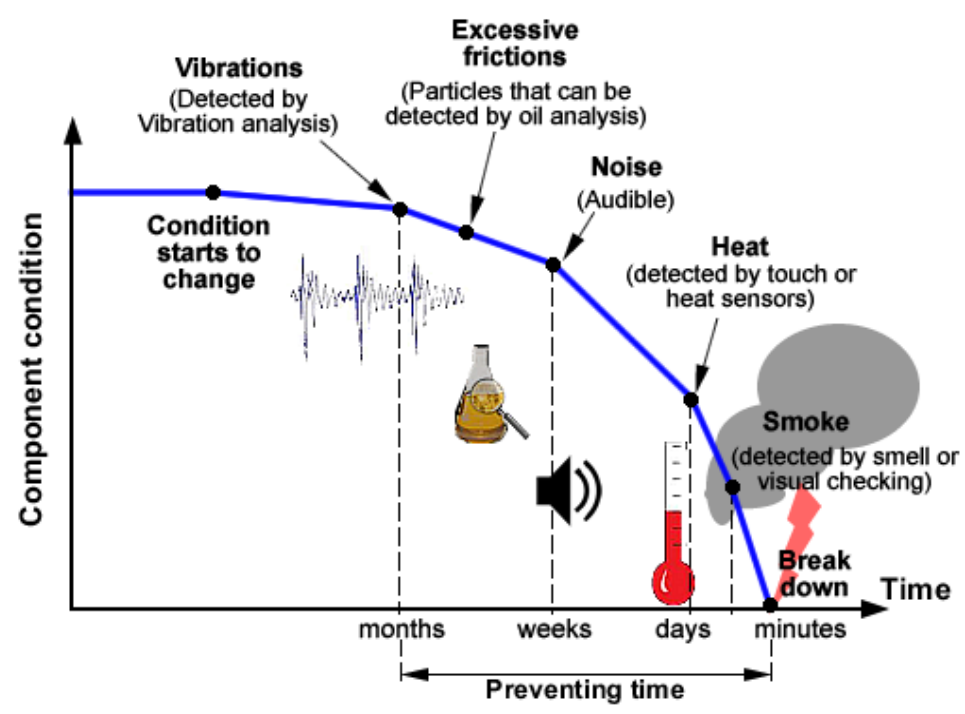

As a subsystem monitoring technique, VA is applied to such WT components as shafts, bearings, gearboxes, and blades. In WTs or wind farms, CM via the VA's extreme false alarm levels can provide information on the incorrectness of vibration signals from the recording process (e.g., in the case of a faulty sensor). To minimize the risk of anomalies, which is increased in a wind farm due to the greater number of WTs, Jablosky et al. [59] developed an algorithm for the automatic validation of vibration signals in the distributed monitoring system of a wind farm. Based on amplitude validation, the vibration data are validated via an original implementation of Parseval's theorem, in addition to the novel idea of a so-called "N-point" rule, which is a simple yet powerful in automatic signal error detection.

The WTCM techniques with VA are standardized in ISO10816 [60], which define the positioning and use of sensors. VA methods are easy to implement in existing equipment and have a high level of interpretation, making it easy to locate the exact faulty component. Nevertheless, this approach implies the use of additional hardware and software, which increases the production costs. Additionally, it is difficult to use sensors to detect low-frequency faults [28].

\subsubsection{OA}

Oil debris monitoring has been proven as a viable CMT for the early detection and tracking of damage in bearing and gear elements in WT gearboxes [61]. Indeed, $80 \%$ of gearbox problems can be attributed to the bearings, which subsequently lead to damage to the gearing [62]. 
In most cases, oil is pumped through the component in a closed-loop system, and metal debris from cracked gearbox wheels or bearings is caught by a filter. The amount and type of metal debris can indicate the health of the component. OA has three main purposes [61]: (i) to monitor the lubricant; condition and reveal whether the system fluid is healthy and fit for further service or requires a change; (ii) to ensure the oil quality (e.g., contamination by parts, moisture); and (iii) to safeguard the components involved (part characterization). Six main tests are generally employed in the OA process: [57,63-65]:

- Viscosity analysis;

- Oxidation analysis;

- Water content or acid content analysis;

- Particle count analysis;

- Machine wear analysis;

- Temperature.

OA techniques can be divided into two categories: real-time continuous monitoring and offline oil sample analysis [66]. These processes are typically executed off line by taking samples. However, online real-time oil debris monitoring may be desirable for applications in which failure modes develop rapidly or when accessibility is limited. In this case, it is advisable to install several sensors in the gearbox lubrication loop to analyze different characteristics. This approach will increase the reliability and accuracy of the analyses [53,64].

The technology for on-line detection can be broadly divided into three subcategories depending on the sensing techniques applied [4]: electromagnetic sensing, flow or pressure-drop sensing, and optical debris sensing. In terms of cost, size, accuracy, and development, suitable oil monitoring technologies are online ferrography, selective fluorescence spectroscopy, scattering measurements, Fourier transform infrared (IR) spectroscopy, photo acoustic spectroscopy, and solid-state viscometry [62,64]. Du and Zhe [67] developed a high-throughout, high-sensitivity inductive sensor for the detection of micro-scale metallic debris in nonconductive lubrication oil. The device is able to detect and differentiate ferrous and non-ferrous metallic debris in lubrication oil with high efficiency.

Although OA is the only method for detecting cracks in the internal gearbox, this approach has two main limitations. First, it cannot detect failures outside the gearbox, and second, use of this equipment for online monitoring is highly expensive. For these reasons, offline monitoring of oil samples is often used $[28,68]$.

\subsubsection{Temperature Measurement (TM)}

Monitoring the temperature of the observed component is one of the most common methods of $\mathrm{CM}$ [56]. TM aids in detecting the presence of any potential failure related to temperature changes in the equipment. In the wind energy industry, TM is applied on such components as bearings, fluids (oil), and generator windings, among others [53,69]. Optical pyrometers, resistant thermometers, and thermocouples are a subset of the sensors used in TM [70]. Unlike thermography, TM provides information on the ongoing deterioration process in the component from excessive mechanical 
friction due to faulty bearings and gears, insufficient lubricant properties, and loose or bad electrical connections [53].

$\mathrm{TM}$ is reliable because every piece of equipment has a limited operational temperature. However, temperature develops slowly and is not sufficient for early and precise fault detection [71]. Additionally, the measured temperature can also be influenced by the surroundings. Therefore, TM is rarely used alone but often as a secondary source of information. In this case, the primary source could be vibration monitoring [32,71].

\subsubsection{SM}

$\mathrm{SM}$ is a renowned technique for structural health monitoring (SHM) and is becoming increasingly important in the WT industry, where it is applied to blades and towers; SM is commonly used in laboratory settings for blade lifetime testing [16,51,72,73]. Measurements are gathered with sensors, i.e., so-called metal foil strain gauges, and the finite element method is commonly used to process the acquired data $[73,74]$. Strain gauges can be placed randomly on the blade, and the distribution varies according to the number of transducers. However, strain gauges are not robust over the long term, and more robust sensors might offer an interesting application area [51,57].

Currently, certain WT manufacturers incorporate fiber-optic sensors into the blades to reduce connections with the data logger and permit little to no weakening of the signal over a considerable distance. With the latest fiber optic sensing technologies, monitoring of stresses on the blades during rotation is easier and more accurate [27,75-77]. Kreuzer [73], Bang et al. [74] and Schroeder et al. [78] investigated the development of a high-speed-fiber Bragg-grating-based sensor array system for strain-based deflection shape estimation of WT structures.

\subsubsection{Optical Fiber Monitoring (OFM)}

OFM is growing as a reliable and cost-effective technique for WT SHM [71]. A network of sensors can be embedded in the blade structure to enable the measurement of five parameters that are critical to SHM. The five parameters include: (i) SM for monitoring the blade loading and vibration level; (ii) TM for likely over-heating; (iii) acceleration measurement for monitoring the pitch angle and rotor position; (iv) crack detection measurements; and (v) lightning detection for measuring the front steepness, maximum current, and specific energy [79-82].

The optical fibers must be mounted on the surface or embedded into the body of the monitored WT components. Therefore, OFM is complicated and expensive in real-world applications compared with other CM and fault detection methods $[83,84]$. However, due to technological progress, it is expected that the cost of OFM for WT SHM will decrease considerably in the future.

\subsubsection{Subsystem CM Techniques Based on NDT}

Malhotra et al. [54] defined NDT as "an examination, test, or evaluation performed on any type of test object without changing or altering it in any way". This is often done in order to determine the absence or presence of conditions or discontinuities that may have an effect on the usefulness or serviceability of the monitored object. NDTs may also be conducted to measure other tested object 
characteristics, i.e., size, dimension, configuration, or structures, including alloy content, hardness, and grain size. Nevertheless, these approaches are largely applied to localized areas. Thus, NDT technologies require more accurate prior knowledge of probable damage locations as well as the use of dedicated sensors [56].

\subsubsection{VI}

Based on human sensory capabilities, VI or observation is undoubtedly one of the oldest CMT and can serve as a supplement to other CMTs. VI includes the detection of sounds emitted by a functioning system, touch (temperature and vibration checking), and VI (e.g., deformation and aspects). This approach is generally used to monitor such components as rotor blades, nacelles, slip rings, yaw drives, bearings, generators, and transformers [53,85].

In several cases, VI is of great importance in identifying a problem that was not identified by other CMTs. Such cases may include loose parts, connections, terminals, and components; visibly worn or broken parts; excessive temperatures that reflect through the structure or housing, oil leakages, corrosion, chattering gears, or hot bearing housings [85-87]. Nevertheless, VI is limited to the identification of damages that are visible on the surface of a structure. Moreover, VI is labor intensive and highly subjective because the results depend on the experience and judgment of the inspector [88].

Today, the industry is implementing remote VI technologies to inspect gearboxes, WT blades, and other critical components [89]. AIT Inc. has developed a video boroscope or videoscope used to inspect the interior areas that are not accessible and can be efficient in revealing hairline cracks, corrosion, pitting, rubbing, and other defects [85]. Moreover, the AutoCopter ${ }^{\mathrm{TM}}$ Corporation [87] has developed a flying remote VI device that enables inspection of WTs, thus increasing reliability and the number of daily inspections while eliminating the risk of personal injury.

\subsubsection{Acoustic Emission (AE)}

AE phenomena are based on the release of energy in the form of transitory elastic waves within a material via a dynamic deformation process [90]. Typically, sources of AE within a material are [91,92] crack initiation and propagation, breaking of fibers, and matrix cracking and fretting between surfaces at de-bonds or de-laminations. Unlike VA, AE can detect failures characterized by high-frequency vibrations ranging from $50 \mathrm{kHz}$ to $1 \mathrm{MHz}$ [93]. Piezoelectric transducers and optic fiber displacement sensors are often employed in this approach [94]. The most commonly measured AE parameters for diagnosis are amplitude, root mean square (RMS) value, energy, kurtosis, crest factor, counts, and events [95].

This method is typically applied for fault detection in gearboxes, bearings, shafts, and blades, and its advantages include a large frequency range and a relatively high signal-to-noise ratio. The main drawback of AE is its cost. Furthermore, only a few types of faults occur in the high-frequency range. Another limitation of $\mathrm{AE}$ is the attenuation of the signal during propagation. Therefore, an AE sensor must be located as close to its source as possible [96], which may pose a practical constraint in applying AE to certain wind machines.

Research was carried on the combined use of AE and VA data [97-99]. Soua et al. [99] presented the results of a combined vibration and $\mathrm{AE}$ monitoring effort that was performed over a continuous 
period of five years on an operating WT. Good results were obtained for the detection of defects, most notably in the gearbox, using special digital processing techniques, such as similarity analysis. Tan et al. [96] carried out a comparative experimental study on the diagnostic and prognostic capabilities of AE, VA, and spectrometric OA for spur gears and observed that based on the analysis of RMS levels, only the AE technique was more sensitive in detecting and monitoring faults than either the vibration or spectrometric OA.

\subsubsection{UTTs}

UTTs are extensively used by the wind energy industry for structural evaluation of WT towers and blades [27,92]. This method relies on elastic wave propagation and reflection within the material. Three different techniques can be used for this investigation: pulse-echo (Figure 11), through transmission, and pitch-catch [100,101]. Laser interferometric sensors, air-coupled transducers, electromagnetic acoustic transducers, or contact transducers are a subset of the sensors that can be used as the scanning sensor for acoustic wave field imaging, which is another UTT [72,102].

Figure 11. Principle of the pulse-echo technique used for the investigation of WT blades [100,103]. GFRP: glass fiber reinforced plastic. Reprinted/Reproduced with permission from [100]. Copyright 2008, Kaunas University of Technology.

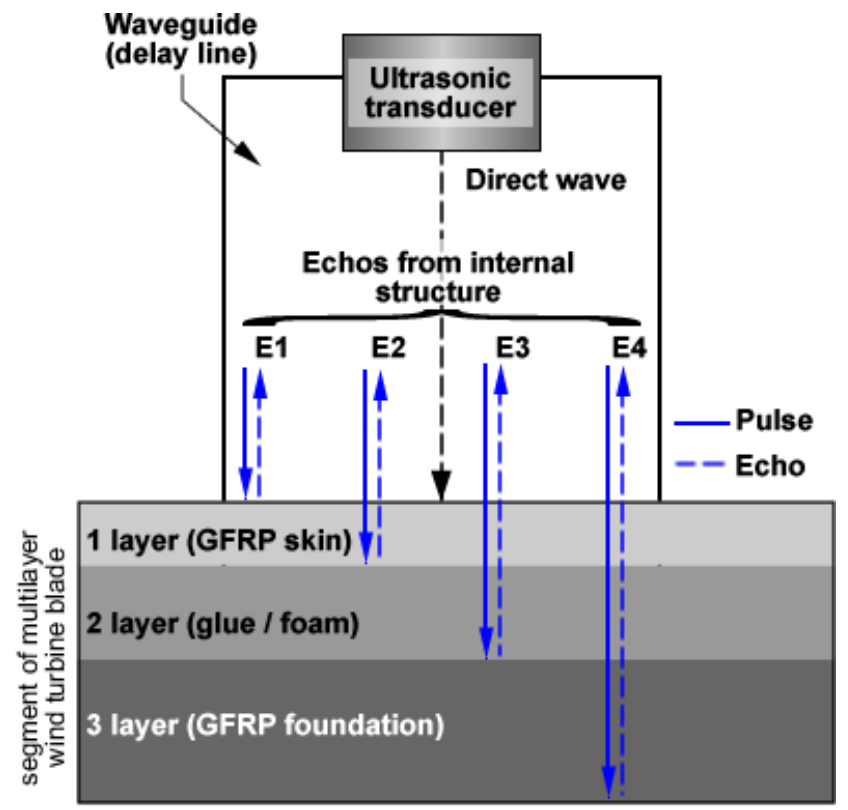

Implementation of UTTs implies one or more of the following measurements: time of flight or delay, path length, frequency, phase angle, amplitude, acoustic impedance, and angle of wave deflection [104]. Thus, signal-processing algorithms, including such time-frequency techniques as the Wigner-Ville distribution, Hilbert-Huang transform, and wavelet transform [100,105], can be used to extract additional information on internal defects.

Ultrasonic testing via wave propagation characteristics allows for the estimation of the location and nature of the detected failure. This approach provides a quick, reliable, and effective method for determining the material properties of the principal turbine components [106]. Ultrasound scanning allows personnel to see below the surface and check the laminate for dry glass fibers and 
de-lamination [107]. Unlike other NDT techniques (i.e., thermographic techniques), acoustic techniques are not as affected by temperature or air humidity [108].

\subsubsection{Thermography Analysis (TA)}

TA provides a wide range of diagnostic and monitoring applications in different equipment and machines, i.e., bearings, gear boxes, conveyor systems, drivers, motors, and electric generators. IR thermography is recognized as one of the most versatile and effective CM tools for use in the WT industry for control and diagnoses of electric parts and mechanical equipment $[109,110]$. This method is based on the fact that all working components emit heat and when a component in the system starts to malfunction, its temperature increases beyond the normal values [56]. IR temperature transmitters and high-resolution IR cameras are the sensors applied in TA, and results are typically interpreted visually [27,111].

Today, TA is primarily used for periodical manual inspection and can be used as a local or global technique because it is possible to assess the damage at the component or system level, depending on the resolution of the camera. However, TA is not appropriate for early fault detection because temperature develops slowly, as mentioned earlier [111,112]. Another important difficulty with TA for WTCM is that monitoring should be performed offline [111]. However, cameras and diagnostic software that are suitable for on-line process monitoring are currently entering the market [57].

\subsubsection{Radiographic Inspection}

Radiography (both film and digital) uses the well-known effects of an X-ray source on one side of a specimen and an X-ray-sensitive receptor on the other side. Although this method does provide useful information on the structural condition of the WT component under inspection, radiographic imaging using X-rays is rarely used in WECS industry [27]. The technique is highly efficient in detecting crack and de-lamination in the blade/rotor and tower structures.

\subsubsection{Other ND WTCM Techniques}

Other techniques are not widespread but are also used in the maintenance of WTs. In many cases, their performance is heavily influenced by the costs or excessive specialization, making them impractical in some situations. Examples are SMs in blades, voltage and current analysis, SPM, and magnetic flux leakage.

\subsection{WT Global System or Nonintrusive CMTs}

Conventional subsystems CMTs (i.e., vibration, lubrication oil, and generator current signal analysis) require the deployment of a variety of sensors and computationally intensive analysis techniques [113]. The use of additional sensors and equipment increases costs and hardware complexity of the WECS. Furthermore, sensors and equipment are inevitably subject to failure, causing additional problems with system reliability and additional OM costs [114]. For these reasons, it is of interest to develop overall CMTs. These techniques are nonintrusive, low cost, and reliable. 
Unlike subsystem CMTs, global systems CMTs enable the extraction of fault features with low calculation time from direct or indirect drives and fixed- or variable-speed WTs. In addition, these techniques can all be used in online and thus increase the WT reliability while reducing the downtime and OM costs [113-115]. Certain overall WTCM approaches include performance monitoring, power curve analyses, electrical signature, and supervisory control and data acquisition (SCADA) system data analysis.

\subsubsection{Performance Monitoring or the Process Parameter Technique}

In WT performance monitoring, parameter readings of the capacity factors of the plant, power, wind velocity, rotor speed, and blade angle are compared with the values in operator manuals or manufacturer performance specifications to determine whether the system is performing at optimum efficiency. The relationships among power, wind velocity, rotor speed, and blade angle can be used for safeguarding purposes, and an alarm is generated in the case of large deviations. The detection margins are large to prevent false alarms [51,53]. Today, more intelligent usage of the signals based on parameter estimation and trending is not a common practice in the WT industry [51].

\subsubsection{Power Signal Analysis}

Power quality is a high-interest area for WTCM because quality could degrade as a result of wind speed turbulence and switching events. From a global viewpoint, the mechanical power (torque times speed) measured on the WT drive shaft and the total three-phase electrical power measured from the terminals of the generator are the input and output of a WT system, respectively. Both energy flows are disturbed by WT abnormalities caused by mechanical or electrical faults [115]. Significant variations in the WT drive train torque are generally signs of abnormalities. Faults in the drive train cause either a torsional oscillation or shift in the $T / \omega$ ratio. By monitoring this ratio, certain fault conditions can be detected. For example, torque oscillations can be detected in a blade or rotor imbalance condition in the WT [71,116].

Peak power output, reactive power, voltage fluctuations, and harmonics greatly influence the power quality [117-120]. As an example, for a healthy WT, the output current is assumed to be sinusoidal:

$$
i_{H}(t)=\mathrm{a} \cos \left(\omega_{1} t\right)
$$

A failure will cause a vibration in the shaft rotation at a certain frequency that can be detected by vibration sensors. The new shaft rotating speed is given by $[121,122]$ :

$$
\omega_{F}(t)=\omega_{1}+\cos \left(\omega_{2} t\right)
$$

Therefore, the instantaneous phase for a faulty WT can be obtained:

$$
\theta_{F}(t)=\int_{0}^{t} \omega_{F}(t) d t=\omega_{1}(t)+\gamma \sin \left(\omega_{2} t\right)
$$

The current for the faulty WT can then be written as:

$$
i_{F}(t)=a \cos \left[\omega_{1} t+\gamma \sin \left(\omega_{2} t\right)\right]=a \cos \left(\omega_{1} t\right) \cos \left(\gamma \sin \left(\omega_{2} t\right)\right)-a \sin \left(\omega_{1} t\right) \sin \left(\gamma \sin \left(\omega_{2} t\right)\right)
$$


If we assume $c \ll \omega$, thus $\gamma \ll 1$. As a result, $\cos \left(\gamma \sin \left(\omega_{2} t\right)\right) \approx 1$ and $\sin \left(\gamma \sin \left(\omega_{2} t\right)\right)=\gamma \sin \left(\omega_{2} t\right)$. We will finally obtain:

$$
i_{\mathrm{F}}(t)=\mathrm{a} \cos \left(\omega_{1} t\right)-\mathrm{a} \gamma \sin \left(\omega_{1} t\right) \sin \left(\omega_{2} t\right)=\mathrm{a} \cos \left(\omega_{1} t\right)-\frac{\mathrm{a} \gamma}{2} \cos \left(\left(\omega_{1}-\omega_{2}\right) t\right)+\frac{\mathrm{a} \gamma}{2} \cos \left(\left(\omega_{1}+\omega_{2}\right) t\right)
$$

where $i_{H}(t)$ and $i_{F}(t)$ are the instantaneous currents for healthy and faulty WT, respectively; $\omega_{1}$ is the angular shaft rotation speed for a healthy WT; $\omega_{2}$ is the angular shaft rotation speed generated by the fault; $\omega_{\mathrm{F}}$ is the shaft rotation speed for a faulty WT; a is the amplitude of the instantaneous current for a healthy WT; $c$ is the amplitude of the current due to the WT fault; and $\gamma=\mathrm{c} / \omega$. a, c and $\gamma$ are constants values. Frequency demodulation is used for feature extraction from Equation (7).

A mechanical failure can also lead to amplitude modulation of the output current. For a three-phase generator, the stator current $i_{k}(t)(k=1,2,3)$ can be described in a discrete form as $[121,123]$ :

$$
i_{k}(n)=\mathrm{a}_{k}(n) \cdot \cos \left(\omega n-\Phi_{k}\right)
$$

where $n=0, \ldots ., N-1$ is the sample index ( $N$ being the total number of received samples); and $\Phi_{k}=2 k \pi / 3$ is the phase parameter. The angular frequency $\omega$ is equal to $2 \pi f / F_{\mathrm{e}}$, where $f$ and $F_{\mathrm{e}}$ are the supply and sampling frequencies, respectively. The amplitude $a_{k}(n)$ is related to the fault as follows:

- For a healthy WT, $a_{k}(n)$ is constant and there is no amplitude modulation;

- For a faulty WT, $a_{k}(n)$ is time variant and the current signal is modulated in amplitude.

Amplitude demodulation can be used for feature extraction using various techniques, such as the Concordia transform or Hilbert transform.

Wakui and Yokoyama [124] developed a sensorless wind-speed performance-monitoring method for stand-alone vertical-axis WTs using numerical analyses in a dynamic simulation model. Yang et al. [113,125,126] and Watson et al. [122] proposed a wind turbine condition monitoring technique (WTCMT) that uses the generator output power and rotational speed to derive a fault detection signal. The technique is based on a detection algorithm using a continuous-wavelet-transform-based adaptive filter to track the energy in the prescribed time-varying fault-related frequency bands in the power signal. A probabilistic model of the power curve based on copulas was developed by Gill et al. [127], for CM purposes. Copula analysis is likely to be useful in WTCM, particularly in early recognition of incipient faults, such as blade degradation, yaw, and pitch errors.

\subsubsection{WTCM Based on Signature Analysis (SA)}

SA is a simpler but more inclusive WTCM technique. Intensive research efforts have been focused on the use of SA to predict or detect electrical and mechanical faults in WECSs. Different signals can be detected (i.e., voltages, power, currents, or stray flux), and SA can be used to detect various faults (i.e., broken rotor bars, bearing failures, air gap eccentricity, and unbalanced rotors and blades) [50,128]. Yazidi et al. [129] proposed a monitoring system for WTs with double-fed induction generators based on stator and rotor current signatures. Different tests were performed in this work, and relevant results were obtained. The proposed CMS was efficient for detection of rotor and stator asymmetry in a double-fed induction machine connected to a back-to-back converter. A similar investigation was carried out by Douglas et al. [130]. 
Yang et al. [131] proposed a CMT based on both electrical and mechanical signatures. In addition to its versatile function, i.e., its ability to detect both mechanical and electrical faults, this technique removes the negative influence of variable wind in the machine CM. This work also investigated the possibility of detecting a WT mechanical fault (e.g., rotor imbalance fault and drive train mechanical fault) via power signal analysis.

\subsubsection{WTCM Based on SCADA Data Analysis}

In most modern WTs, SCADA systems are now common. The WTCM using SCADA data analysis is cost effective (data collection and sensor networks already in place) and reliable because it relies on the interpretation of SCADA data [132]. The SCADA system collects information extensively from key WT subassemblies using sensors fitted to the WT, i.e., anemometers, thermocouples, and switches. The operational data reflect either turbine status or measurements of signals, such as wind speed and direction, temperatures, currents, or pressures. This information can effectively reflect the real-time condition of a WECS, and by analyzing SCADA data, the relationship between different signals can be observed and the health of WT components deduced [133]. Neural networks and fuzzy logic are other examples of the common tools for data analysis. An overview of WTCM based on SCADA data analysis is presented in Figure 12.

Figure 12. Overview of wind turbine condition monitoring (WTCM) based on supervisory control and data acquisition (SCADA) data analysis. FIS: fuzzy interference system.

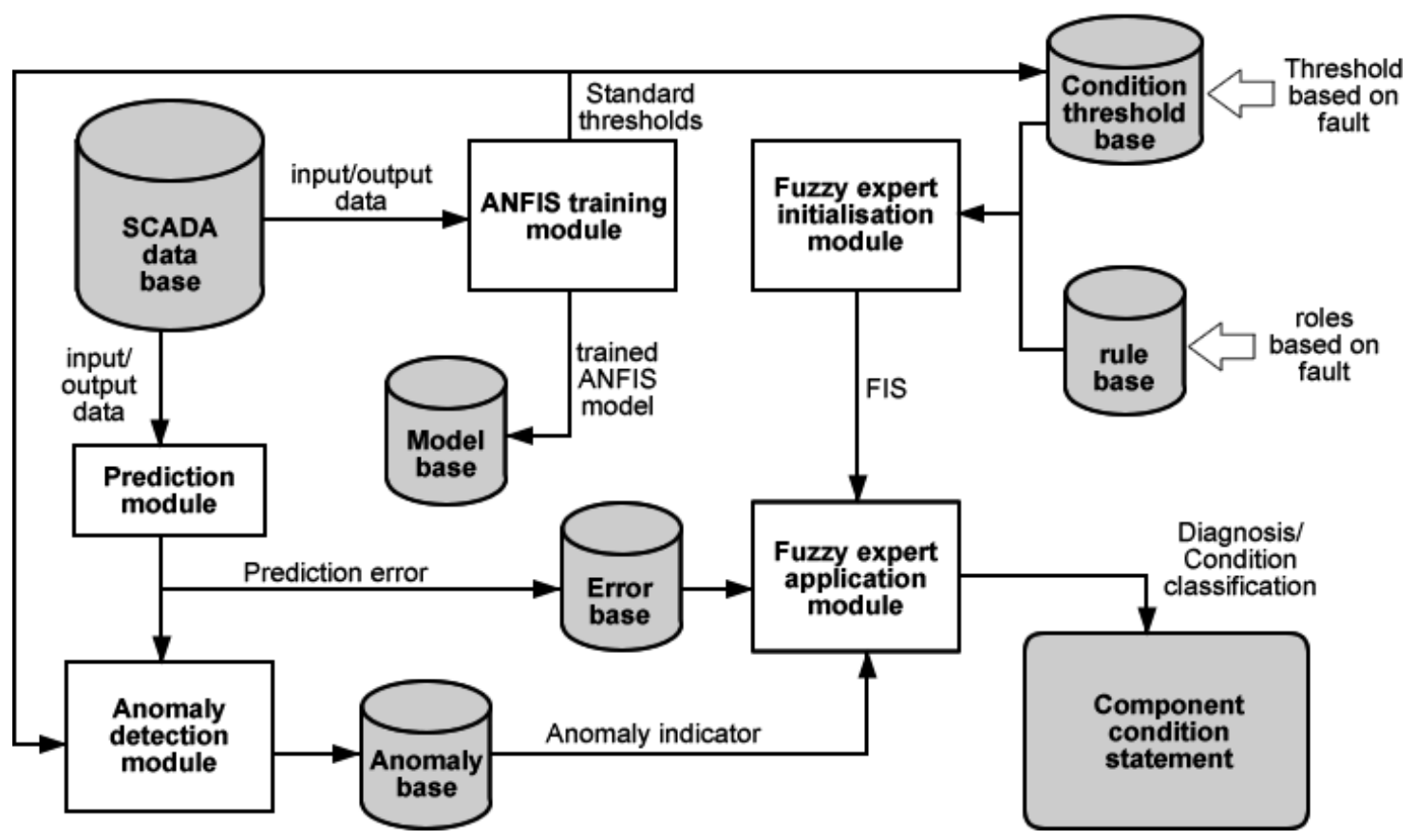

Several recent studies on SCADA data for WECS CM can be found in the literatures [132,134-137]. A wind turbine condition monitoring system (WTCMS) based on SCADA using normal behavior models and fuzzy logic was presented in [135]. This CMS is designed to detect trends and patterns in SCADA data and predict possible failures. Another recent research study by Li et al. [136] focused on improving the fuzzy synthetic condition assessment of a WT generator system. The results indicated 
that the evaluation of dynamic limits and deterioration degree functions for the characteristic variables for WECSs could be improved by analyzing SCADA data with the improved fuzzy synthetic model.

However, the WT SCADA system does not collect all of the information necessary to conduct a full $\mathrm{CM}$ of a WT because it was not initially designed for CM purposes. Furthermore, although SCADA techniques are widely applied to WT, the data rate of once every 5-10 $\mathrm{min}$ is too slow for most rotating machine fault diagnoses $[116,131,133]$. Another concern is that the values of SCADA data vary over wide ranges under varying operational conditions, and it is difficult to detect an incipient fault from raw SCADA data without an appropriate data analysis tool [137].

This section provides a status update on different methods and techniques used for WTCM. Table 1 presents an overview on the state of the art for WTCMSs, including possible failures and corresponding monitoring techniques for various WT components and subsystems. The following section focuses on new trends in WTCM with respect to the wind industry's evolution, and implications for challenges in the research area will be discussed based on these tendencies.

\section{New Trends and Future Challenges in WTCMTs}

The state-of-the-art maintenance strategy in the wind machine industry is defined by the implementation of on-line continuous CMS. The authors of [133,138] conducted respective surveys of: (i) commercially available CMSs for WT; and (ii) commercially available SCADA data analysis tools for WT health monitoring. The survey in [138] elaborated on the methods used by 20 suppliers and concluded that nearly all of them focus on the same subassemblies, i.e., blades, main bearings, gearbox internals, gearbox bearings, and generator bearings.

Furthermore, VM, OM, and fiber optic monitoring are the most frequently used monitoring techniques. The study in [133] addressed 17 SCADA data analysis tools for WTCM. Among the 17 products, three were developed by WT manufacturers, two by renewable energy consultancies, up to nine by industrial software companies, two by an electrical equipment provider, and only one by a WT operating company.

\subsection{New Trends in WTCMSs}

The current trend in the wind energy industry is the use of larger WTs in remote locations, which are increasingly situated offshore for optimal wind conditions. Both the size and location factors have led to maintenance challenges that are unique compared with those of traditional power generation systems [66]. To cope with this reality, WTCMS manufacturers must improve the existing monitoring techniques and/or develop more appropriate techniques. The future goal in CMS is to continue to minimize the efforts required from operators through the use of intelligent software algorithms and automated analysis.

The WT industry is moving toward intelligent machine health management (IMHM), which is a fourth-generation maintenance strategy. The final objective is to provide WECSs that are capable of understanding and making decisions without human intervention. This goal implies the use of intelligent condition-based maintenance systems based on RCM mechanisms. Thus, the following tendencies can be mentioned with respect to the new tendencies in the WTCM industry [52]. 
Table 1. Overview of possible failures and monitoring techniques for various WTs components and subsystems. OA: oil analysis; AE: acoustic emission; SM: strain measurement; VI: visual inspection; SPM: shock pulse method; and OM: operation and maintenance.

\begin{tabular}{|c|c|c|c|c|}
\hline WT subsystems & Components & $\begin{array}{c}\text { Possible failures } \\
\end{array}$ & Component or subsyst & em monitoring \\
\hline \multirow{3}{*}{ Rotor } & Blades & Deterioration, cracking, and adjustment error & Ultrasound, and active thermography & \multirow{3}{*}{ Torque, AM, SM, and VI } \\
\hline & Bearings & $\begin{array}{l}\text { Spalling, wear, defect of bearing shells and } \\
\text { rolling element }\end{array}$ & $\begin{array}{l}\text { Vibration, OA, AE, SPM, } \\
\text { and performance monitoring }\end{array}$ & \\
\hline & Shaft & Fatigue, and crack formation & Vibration & \\
\hline \multirow[b]{3}{*}{ Drive train } & Main shaft bearing & Wear, and high vibration & Vibration, SPM, temperature, and AE & \multirow{3}{*}{$\begin{array}{l}\text { Torque, power signal } \\
\text { analysis, thermography, } \mathrm{AE}, \\
\text { and performance monitoring }\end{array}$} \\
\hline & Mechanical brake & $\begin{array}{c}\text { Locking position } \\
\end{array}$ & Temperature & \\
\hline & Gearbox & $\begin{array}{c}\text { Wearing, fatigue, oil leakage, insufficient lubrication, } \\
\text { braking in teeth, displacement, and eccentricity of } \\
\text { toothed wheels }\end{array}$ & $\begin{array}{c}\text { Temperature, vibration, SPM, } \\
\text { particles in oil, and AE }\end{array}$ & \\
\hline \multicolumn{2}{|c|}{ Generator } & $\begin{array}{c}\text { Wearing, electrical, problems, slip rigs, } \\
\text { winding damage, rotor asymmetries, bar break, } \\
\text { overheating, and over speed }\end{array}$ & \multicolumn{2}{|c|}{$\begin{array}{l}\text { Generated effect, temperature, vibration, SPM, OM, torque, } \\
\text { power signal analysis, electrical effects, process parameters, } \\
\text { performance monitoring, and thermography }\end{array}$} \\
\hline \multirow{4}{*}{$\begin{array}{l}\text { Auxiliary } \\
\text { systems }\end{array}$} & Yaw system & Yaw motor problem, brake locked, and gear problem & \multicolumn{2}{|c|}{ Motor current } \\
\hline & Pitch system & Pitch motor problem & \multicolumn{2}{|c|}{ OM } \\
\hline & Hydraulic system & Pump motor problems, and oil leakage & \multicolumn{2}{|c|}{ OM, process parameter, performance monitoring } \\
\hline & Sensors & Broken, and wrong indication & \multicolumn{2}{|c|}{ Thermography } \\
\hline \multirow{3}{*}{$\begin{array}{l}\text { Electrical } \\
\text { system }\end{array}$} & Control system & Short circuit, component fault, and bad connection & Current consumption, and temperature & \multirow{3}{*}{ Thermography, and VI } \\
\hline & Power electronics & Short circuit, component fault, and bad connection & Current consumption, and temperature & \\
\hline & High Voltage & Contamination, and arcs & Arc guard, temperature & \\
\hline \multirow[b]{2}{*}{ Tower } & Nacelle & Fire, and yaw error & Smoke, heat, flame detection & \multirow[b]{2}{*}{ Vibration, SPM, SM, and VI } \\
\hline & Tower & $\begin{array}{c}\text { Crack formation, fatigue, vibration, } \\
\text { and foundation weakness }\end{array}$ & tos & \\
\hline \multicolumn{2}{|c|}{ System transformer } & $\begin{array}{l}\text { Problem with contamination, breakers, } \\
\text { disconnectors, and isolators }\end{array}$ & \multicolumn{2}{|c|}{ Thermography } \\
\hline
\end{tabular}




\subsubsection{Toward Smart Monitoring}

The purpose of this effort is to develop a CMS that is self-contained. Such systems could be operated by trained personnel but would not require specialists for the interpretation of results because a smart monitoring system will be able to perform classification and prediction operations [139]. Therefore, the number of turbines that a technician is able to oversee might double. Moreover, smart WTCMSs will integrate built-in hardware auto-diagnostics that continuously check all sensors, cabling, and electronics for any faults, signal interruption, shorts, or power failures. Any malfunctions trigger an alarm. Indeed, false warnings and false alarms occur on a regular basis with actual CMSs [119,140-143]. The use of smart monitoring will aid in avoiding such situations.

Automation of $\mathrm{CM}$ and diagnostic systems will also be an important development as WT operators acquire a larger number of turbines and manual inspection of data becomes impractical. Furthermore, it is essential that methods for reliable, automatic diagnosis are developed with consideration of multiple signals to improve detection and increase operator confidence in alarm signals $[25,138]$.

\subsubsection{Necessity of Remote and E-Monitoring}

Considering: (i) the tendency toward the use of offshore WTs; and (ii) the fact that wind parks are geographically dispersed and often located in remote areas, cost considerations make it necessary to reevaluate the traditional monitoring setup. Thus, remote CM of WECSs is gaining popularity in the industry and can be implemented as either standalone or networked systems. Remote CM involves monitoring the condition of a component at a location far away from the immediate vicinity of the component in question. E-monitoring and $\mathrm{CM}$ using the Internet improves remote monitoring by providing worldwide remote capabilities. Because browsers reside on many platforms, internet-based CMSs can be accessed by multiple users working on any type of operating system [144-146]. In short, wireless technologies will help to optimize the cost and efficiency of WTCMSs.

\subsubsection{In-Service SHM}

Given the increased size of modern turbines and their growing cost and fabrication sophistication, i.e., high-tech, complex, and constructed with composite materials, SHM is becoming increasingly important to both operators and insurers [143]. The necessity for continuous in-service SHM is a reality because these complex structures are fragile. For example, if any blade fails, the rotor can become unbalanced and might lead to the destruction of the entire WT [147]. Therefore, it is important to acquire early indications of structural or mechanical problems that will allow operators to better plan for maintenance, possible operation of the machine in a de-rated condition rather than taking the turbine off-line, or, in the case of an emergency, shutdown of the machine to avoid further damage.

The development of real-time, remote, wireless, and smart SHM is playing an increasingly important role. Such monitoring systems designed for the continuous assessment of structural performance and safety should be comprehensive and include functions for self-diagnostics and management of the SHM system $[88,148,149]$. Similar SHM techniques are already used in certain industries, such as aeronautics, where they are applied for the SHM of aircraft composite structures [150,151]. 
Additionally, there is a tendency to require ambient energy harvesting for powering wireless sensors $[152,153]$. However, a major limitation in the field of energy harvesting is the fact that the energy generated by harvesting devices is far too small to directly power most electronics. Therefore, (i) efficient, innovative, and adapted methods of storing electric energy; and (ii) more energy-efficient sensors are the key technologies that will allow energy harvesting to become a source of power for electronics and wireless sensors [154-156].

Two different approaches are emerging in the field of WTSHM. The first and more practical approach is the development of appropriate non-contact and remote NDT/inspecting technologies for in-service WTSHM because non-contact and remote NDTs have overwhelming advantages in terms of on-line testing and inspection. The second approach consists of equipping the WT with a SHM system consisting of a network of sensors, data acquisition units, and an on-site server installed in the WT maintenance room. The sensors (accelerometers, displacement transducers, and temperature sensors) are placed at different levels inside and outside the steel tower and on the foundation of the WT. In this last case, microchip path antennas are increasingly used for sensing, ambient energy harvesting, and data transmission [157-160].

\subsubsection{Integration and Interaction of Monitoring and Control Systems}

Today's standard CMSs essentially still operate in stand-alone mode, i.e., independent of the WT controller. The CMSs are increasingly integrated with control functions and included in maintenance concepts [161]. The full integration of CM capabilities within the WT control system is beneficial with regard to three different aspects: (i) cost benefits; (ii) technical benefits; and (iii) quality benefits. An overview of the benefits of controller-integrated CMSs was presented in [162,163] and can be summarized as follows:

Cost benefits:

- Lower hardware costs due to industrial mass production and fewer components;

- Lower installation and cabling costs due to integration in the existing control cabinet and communication with the main controller via bus systems;

- Fewer required parts because no additional voltage transformers, communication modules, uninterruptible power supply (UPS), or similar devices are needed;

- Reduced analysis because fewer false alarms occur.

Technical benefits:

- No measurement if interference signals are present;

- Higher-quality raw data for analysis;

- Fewer false alarms;

- Reduced scatter leads to improved fault detection;

- Integration of further signals (e.g., temperature, pressure, and current) enables integrated signal/system monitoring. 
Quality benefits:

- Reliable hardware from established industrial suppliers;

- Mass production with high-quality standards.

\subsubsection{Estimation of the Remaining Component Life Service}

The limited accessibility of offshore wind farms requires new maintenance and repair strategies. In fact, offshore wind farms are likely to be unreachable for several months out of a year, especially if sited in the North Sea and polar regions [164,165]. Thus, maintenance and repair activities must be carried out during seasons in which the turbines are accessible. Components that are likely to fail during periods of inaccessibility must be replaced. This approach is referred to as a "condition-dependent and predictive maintenance and repair strategy" $[38,166]$. Such a strategy requires comprehensive knowledge of the actual condition and the remaining lifetime of the turbine components. Such knowledge can be provided by CMSs. For those components, a count of their lifetime fatigue load can provide information on the condition and remaining lifetime. However, current CMSs are not able to assure that a given component will not fail, nor can they prevent a failure.

\subsection{Future Research Challenges in WTCMTs}

Although CM technologies face various challenges in WT applications, they are still necessary and valuable. As with any technology, there is room for improvement such that these systems can be better utilized to benefit the wind industry. Based on the provided discussion on new trends in WTCM, selected key points that must be addressed by further research are listed as follows:

- $\quad$ Determine the most cost-effective measurement or monitoring strategy.

- Automate the "experts" in data interpretation to automate actionable recommendations.

- Develop reliable and accurate prognostic techniques.

- Improve the use of SCADA system data (normally only stored at 10-min intervals) to provide a more reliable, flexible, and efficient tool for automatic WT monitoring and control [133].

- Develop smart, wireless, and energy-efficient sensors that will offer opportunities for placing sensors in difficult-to-reach locations, electrically noisy environments, and mobile applications in which wires cannot be installed.

- Focus on providing the newest and industry-proven signal processing algorithms for extracting the key features of a signal to predict machine component health.

- Combine numerical simulation analysis with testing, inspecting, and monitoring technologies. The finite element method is one such interesting tool that has traditionally been used in the development of WT blades, primarily to investigate the global behavior in terms of eigenfrequencies, tip deflections, and global stress/strain levels [167]. An advantage of using the finite element method is that complex load cases that represent actual wind conditions can be analyzed once the model is set up and calibrated. Moreover, this method will considerably reduce the cost of testing, inspecting, and monitoring for WTs, especially SHM.

- Develop innovative, adapted, and efficient methods of harvesting and storing electric energy for autonomous and wireless sensors. 
Other technological advances that must be developed in WTCMs include advancements in diagnostic and prognostic software, acceptance of communication protocols, and developments in maintenance software applications and computer networking technologies [146]. Although these future research areas may appear challenging to address, they also represent great opportunities for CM to boost the success of the wind industry by reducing the COE and increasing its competitiveness.

\section{Conclusions}

WT technology has greatly advanced in a relatively short time span. Among the technologies successfully transferred from applications in other industries, CMSs enable early detection and diagnosis of potential component failures and serve as a platform for implementing CM practices.

This paper performed an inventory and classification of WTCMTs and has highlighted the fact that a combination of preventive and reactive maintenance strategies can improve reliability, availability, and maintainability of WTs while reducing maintenance costs. An overview of $\mathrm{CM}$ and the maintenance process in the WT industry enabled the presentation of a global diagram linking the various concepts, and a comprehensive review of WTCM techniques and methods was carried out.

For new trends in WTCM, the wind energy industry's tendency to use larger WTs in remote locations implies the need for remote, intelligent, and integrated CMSs. In particular, efforts should be directed toward improving the capacity of CMSs for failure prognostics and determination of remaining equipment life. Finally, this work addressed certain important and challenging areas of research that should be explored for the industry to better cope with the major innovations that are likely to occur in the WTCM industry.

\section{Acknowledgments}

The authors would like to thank the Natural Science and Engineering Research Council of Canada (NSERC) for financially supporting this research. Authors' gratefulness also goes to the editor and four anonymous reviewers for their valuable comments and suggestions that appreciably improved the quality of this paper.

\section{Author Contributions}

Pierre Tchakoua Takoutsing is the main author of this work. This paper provides a further elaboration of some of the results associated to his Ph.D. dissertation. René Wamkeue and Mohand Ouhrouche have supervised the Ph.D. work and thus have supported Pierre Tchakoua Takoutsing's research in terms of both scientific and technical expertise. Fouad Slaoui-Hasnaoui, Tommy Andy Tameghe and Gabriel Ekemb participated in designing the structure of the contributions to fit them into a review of concepts and methods for WTCM. All authors have been involved in the manuscript preparation.

\section{Nomenclature}

$\begin{array}{ll}\text { WT } & \text { Wind turbine } \\ \text { RCM } & \text { Reliability-centered maintenance } \\ \text { CM } & \text { Condition monitoring }\end{array}$




$\begin{array}{ll}\text { OM } & \text { Operation and maintenance } \\ \text { WTCM } & \text { Wind turbine condition monitoring } \\ \text { WTCMS } & \text { Wind turbine condition-monitoring system } \\ \text { WECS } & \text { Wind energy conversion system } \\ \text { COE } & \text { Cost of energy } \\ \text { CMS } & \text { Condition-monitoring system } \\ \text { CMT } & \text { Condition-monitoring technique } \\ \text { FDS } & \text { Fault detection system } \\ \text { DT } & \text { Destructive test } \\ \text { NDT } & \text { Non-destructive tests } \\ \text { VA } & \text { Vibration analysis } \\ \text { OA } & \text { Oil analysis } \\ \text { TM } & \text { Temperature monitoring } \\ \text { SM } & \text { Strain measurement } \\ \text { OFM } & \text { Optical-fiber monitoring } \\ \text { SHM } & \text { Structural health monitoring } \\ \text { VI } & \text { Visual inspection } \\ \text { AE } & \text { Acoustic emission } \\ \text { UTT } & \text { Ultrasonic testing techniques } \\ \text { TA } & \text { Thermography analysis } \\ \text { SCADA } & \text { Supervisory control and data acquisition } \\ \text { SA } & \text { Signature analysis } \\ \end{array}$

\section{Conflicts of Interest}

The authors declare no conflict of interest.

\section{References}

1. Fried, L.; Sawyer, S.; Shukla, S.; Qiao, L. Global Wind Report 2012-Annual Market Update; Global Wind Energy Council (GWEC): Brussels, Belgium, 2013. Available online: http://www.gwec.net (accessed on 22 February 2014).

2. Zhang, P. Small Wind World Report 2012; World Wind Energy Association (WWEA): Bonn, Germany, 2012.

3. Renewables 2012: Global Status Report; REN21: Paris, France, 2012.

4. Ribrant, J. Reliability Performance and Maintenance-A Survey of Failures in Wind Power Systems. Master's Thesis, School of Electrical Engineeringm, KTH Royal Institute of Technology, Stockholm, Sweden, 2005-2006.

5. Hines, V.; Ogilvie, A.; Bond, C. Continuous Reliability Enhancement for Wind (CREW) Database: Wind Turbine Reliability Benchmark Report; Sandia National Laboratories: Albuquerque, NM, USA, 2013. 
6. Walford, C.A. Wind Turbine Reliability: Understanding and Minimizing Wind Turbine Operation and Maintenance Costs; Sandia Report No. SAND2006-1100; Sandia National Laboratories: Albuquerque, NM, USA, 2006.

7. Tchakoua, P.; Wamkeue, R.; Tameghe, T.A.; Ekemb, G. A Review of Concepts and Methods for Wind Turbines Condition Monitoring. In Proceedings of the 2013 World Congress on Computer and Information Technology (WCCIT), Sousse, Tunisia, 22-24 June 2013; pp. 1-9.

8. Fischer, K.; Besnard, F.; Bertling, L. Reliability-centered maintenance for wind turbines based on statistical analysis and practical experience. IEEE Trans. Energy Convers. 2012, 27, 184-195.

9. McMillan, D.; Ault, G. Condition monitoring benefit for onshore wind turbines: Sensitivity to operational parameters. IET Renew. Power Gener. 2008, 2, 60-72.

10. Amayri, A.; Tian, Z.; Jin, T. Condition Based Maintenance of Wind Turbine Systems Considering Different Turbine Types. In Proceedings of the 2011 International Conference on Quality, Reliability, Risk, Maintenance, and Safety Engineering (ICQR2MSE), Xi'an, Shannxi, China, 17-19 June 2011; pp. 596-600.

11. Besnard, F.; Bertling, L. An approach for condition-based maintenance optimization applied to wind turbine blades. IEEE Trans. Sustain. Energy 2010, 1, 77-83.

12. Echavarria, E.; Hahn, B.; van Bussel, G.J.; Tomiyama, T. Reliability of wind turbine technology through time. J. Sol. Energy Eng. 2008, 130, doi:10.1115/1.2936235.

13. Hahn, B.; Durstewitz, M.; Rohrig, K. Reliability of Wind Turbines. In Wind Energy; Springer: Berlin/Heidelberg, Germany, 2007; pp. 329-332.

14. Ahmad, R.; Kamaruddin, S. An overview of time-based and condition-based maintenance in industrial application. Comput. Ind. Eng. 2012, 63, 135-149.

15. Andrawus, J.A.; Watson, J.; Kishk, M. Wind turbine maintenance optimisation: Principles of quantitative maintenance optimisation. Wind Eng. 2007, 31, 101-110.

16. Andrawus, J.A. Maintenance Optimisation for Wind Turbines. Ph.D. Thesis, Robert Gordon University, Aberdeen, UK, April 2008.

17. Hahn, B. Reliability Assessment of Wind Turbines in Germany. In Proceedings of the 1999 Europeen Wind Energy Conference, Nice, France, 1-5 March 1999.

18. Tavner, P.J.; Xiang, J.; Spinato, F. Reliability analysis for wind turbines. Wind Energy 2007, $10,1-18$.

19. Guo, H.; Watson, S.; Tavner, P.; Xiang, J. Reliability analysis for wind turbines with incomplete failure data collected from after the date of initial installation. Reliab. Eng. Syst. Saf. 2009, 94, 1057-1063.

20. Spinato, F.; Tavner, P.J.; van Bussel, G.J.W.; Koutoulakos, E. Reliability of wind turbine subassemblies. IET Renew. Power Gener. 2008, 3, 387-401.

21. Amirat, Y.; Benbouzid, M.E.H.; Member, S.; Bensaker, B.; Wamkeue, R. Condition Monitoring and Fault Diagnosis in Wind Energy Conversion Systems: A Review. In Proceedings of the IEEE International Electric Machines \& Drives Conference, IEMDC '07, Antalya, Turkey, 3-5 May 2007; Volume 2, pp. 1434-1439.

22. Ribrant, J.; Bertling, L. Survey of Failures in Wind Power Systems with Focus on Swedish Wind Power Plants during 1997-2005. In Proceedings of the 2007 IEEE Power Engineering Society General Meeting, Tampa, FL, USA, 24-28 June 2007; pp. 1-8. 
23. Villa, L.F.; Renones, A.; Pera, J.R.; de Miguel, L.J. Statistical fault diagnosis based on vibration analysis for gear test-bench under non-stationary conditions of speed and load. Mech. Syst. Signal Process. 2012, 29, 436-446.

24. Crabtree, C.J.; Feng, Y.; Tavner, P.J. Detecting Incipient Wind Turbine Gearbox Failure: A Signal Analysis Method for On-line Condition Monotoring. In Proceedings of European Wind Energy Conference (EWEC 2010), Warsaw, Poland, 20-23 April 2010; pp. 154-156.

25. Crabtree, C.J. Condition Monitoring Techniques for Wind Turbines. Ph.D. Thesis, Durham University, Durham, UK, February 2011.

26. Aziz, M.A.; Noura, H.; Fardoun, A. General Review of Fault Diagnostic in Wind Turbines. In Proceedings of the 2010 18th Mediterranean Conference on Control \& Automation (MED), Marrakech, Morocco, 23-25 June 2010; pp. 1302-1307.

27. García, F.P.; Tobias, A.M.; Pinar, J.M.; Papaelias, M. Condition monitoring of wind turbines: Techniques and methods. Renew. Energy 2012, 46, 169-178.

28. Hameed, Z.; Hong, Y.S.; Cho, Y.M.; Ahn, S.H.; Song, C.K. Condition monitoring and fault detection of wind turbines and related algorithms: A review. Renew. Sustain. Energy Rev. 2009, $13,1-39$.

29. Lu, B.; Li, Y.; Wu, X.; Yang, Z. A Review of Recent Advances in Wind Turbine Condition Monitoring and Fault Diagnosis. In Proceedings of the IEEE Power Electronics and Machines in Wind Applications, PEMWA 2009, Lincoln, NE, USA, 24-26 June 2009; pp. 1-7.

30. Orsagh, R.F.; Lee, H.; Watson, M.; Byington, C.S.; Power, J. Advance Vibration Monitoring for Wind turbine Health Management; Impact Technologies, LLC: Rochester, NY, USA, 2006.

31. Dhillon, B.S. Engineering Maintenance: A Modern Approach; CRC Press: Boca Raton, FL, USA, 2002.

32. Madsen, B.N. Condition Monitoring of Wind Turbines by Electric Signature Analysis. Master's Thesis, Technical University of Denemark, Copenhagen, Denmark, October 2011.

33. Wang, L.; Yeh, T.-H.; Lee, W.-J.; Chen, Z. Benefit evaluation of wind turbine generators in wind farms using capacity-factor analysis and economic-cost methods. IEEE Trans. Power Syst. 2009, 24, 692-704.

34. Al-Ahmar, E.; Hachemi, M.E.; Turri, S. Wind energy conversion systems fault diagnosis using wavelet analysis. Int. Rev. Electr. Eng. 2008, 3, 646-652.

35. De Oliveria, W.S.; Fernandes, A.J. Cost-effectiveness analysis for wind energy projects. Int. J. Energy Sci. 2012, 2, 15-21.

36. Byon, E.; Ntaimo, L.; Ding, Y. Optimal maintenance strategies for wind turbine systems under stochastic weather conditions. IEEE Trans. Reliab. 2010, 59, 393-404.

37. Blischke, W.R.; Karim, M.R.; Prabhakar Murthy, D.N. Warranty Data Collection and Analysis; Springer: London, UK, 2011.

38. Nilsson, J.; Bertling, L. Maintenance management of wind power systems using condition monitoring systems - Life cycle cost analysis for two case studies. IEEE Trans. Energy Convers. 2007, 22, 223-229.

39. Hameed, Z.; Ahn, S.H.; Cho, Y.M. Practical aspects of a condition monitoring system for a wind turbine with emphasis on its design, system architecture, testing and installation. Renew. Energy 2010, 35, 879-884. 
40. Wiggelinkhuizen, E.J.; Verbruggen, T.W.; Braam, H.; Rademakers, L.W.M.M.; Xiang, J.; Watson, S.; Giebel, G.; Norton, E.; Tipluica, M.C.; MacLean, A.; et al. CONMOW: Condition Monitoring for Offshore Wind Farms. In Proceedings of the European Wind Energy Conference (EWEC2007), Milan, Itlay, 7-10 May 2007.

41. Renewable Energy Technologies: Cost Analysis Series; The International Renewable Energy Agency (IRENA): Abu Dhabi, United Arab Emirates, 2012; Volume 1.

42. Arunraj, N.S.; Maiti, J. Risk-based maintenance-Techniques and applications. J. Hazard. Mater. 2007, 142, 653-661.

43. Sheng, C.; Li, Z.; Qin, L.; Guo, Z.; Zhang, Y. Recent progress on mechanical condition monitoring and fault diagnosis. Procedia Eng. 2011, 15, 142-146.

44. Jardine, A.K.S.; Lin, D.; Banjevic, D. A review on machinery diagnostics and prognostics implementing condition-based maintenance. Mech. Syst. Signal Process. 2006, 20, 1483-1510.

45. Utne, I.B.; Brurok, T.; Rodseth, H. A structured approach to improved condition monitoring. J. Loss Prev. Process Ind. 2012, 25, 148-188.

46. Bengsston, M. On Condition Based Maintenance ant Its Implimentation in Industrial Settings. Ph.D. Thesis, Mälardalen University, Västerås, Sweden, 2007.

47. Bengtsson, M.; Olsson, E.; Funk, P.; Jackson, M. Technical Design of Condition Based Maintenance System-A Case Study using Sound Analysis and Case-Based Reasoning. In Proceedings of the 8th Congress on Maintenance and Reliability Conference, MARCON 2004, Knoxville, TN, USA, 2-5 May 2004.

48. Simeón, E.A.; Álvares, A.J. An Expert System for Fault Diagnostics in Condition Based Maintenance. ABCM Symp. Ser. Mechatron. 2010, 4, 304-313.

49. Maintenance Terminology; SS-EN 13306; Swedish Standards Institute: Stockholm, Sweden, 2011.

50. Popa, L.M.; Jensen, B.-B.; Ritchie, E.; Boldea, I. Condition Monitoring of Wind Generators. In Proceedings of the 38th IAS Annual Meeting, Conference Record of the Industry Applications Conference, Salt Lake City, UT, USA, 12-16 October 2003; Volume 3, pp. 1839-1846.

51. Verbruggen, T. Wind Turbine Operation \& Maintenance based on Condition Monitoring WT- $\Omega$; ECN-C-03-047; Energieonderzoek Centrum Nederland (ECN): Petten, The Netherlands, 2003.

52. Tchakoua, P.; Wamkeue, R.; Slaoui-Hasnaoui, F.; Tameghe, T.A.; Ekemb, G. New Trends and Future Challenges for Wind Turbines Condition. In Proceedings of the 2013 International Conference on Control Automation and Information Sciences (ICCAIS), Nha Trang, Vietnam, 25-28 November 2013; pp. 238-245.

53. Saeed, A. Online Condition Monitoring System for Wind Turbine. Master's Thesis, Blekinge Institute of Technology, Karlskrona, Sweden, 2008.

54. Malhotra, V.M.; Carino, N.J. Handbook on Nondestructive Testing of Concrete; CRC Press: Boca Raton, FL, USA, 2004.

55. Gamidi, S.H. Non Destructive Testing of Structures. Master's Thesis, Indian Institute of Technology, Bombay, Libya, November 2009.

56. Hellier, C.J. Handbook of Nondestructive Evaluation; McGraw-Hill Professional Publishing: New York, NY, USA, 2003.

57. Elforjani, M.A. Condition Monitoring of Slow Speed Rotating Machinery Using Acoustic Emission Technology. Ph.D. Thesis, Cranfield University, Cranfield, UK, June 2010. 
58. Khan, M.M.; Iqbal, M.T.; Khan, F. Reliability and Condition Monitoring of a Wind Turbine. In Proceedings of the 2005 Canadian Conference on Electrical and Computer Engineering, Saskatoon, SK, Canada, 1-4 May 2005; pp. 1978-1981.

59. Jablonsky, A.; Barszcz, T.; Bielecka, M. Automatic validation of vibration signals in wind farm distributed monitoring systems. Measurement 2011, 44, 1954-1967.

60. Mechanical Vibration-Evaluation of Machine Vibration by Measurements on Non-Rotating Parts-Part 1: General Guidelines; ISO 10816-1:1995; International Organization for Standardization (ISO): Geneva, Switzerland, 1995.

61. Barrett, M.P.; Stover, J. Understanding Oil Analysis: How It Can Improve the Reliability of Wind Turbine Gearboxes; Gear Technology: Elk Grove Village, IL, USA, 2013; pp. 104-111.

62. Dupuis, R. Application of Oil Debris Monitoring For Wind Turbine Gearbox Prognostics and Health Management. In Proceedings of the Annual Conference of the Prognostics and Health Management Society 2010, Portland, OR, USA, 10-16 October 2010.

63. Goncalves, A.C.; Campos, J.B. Predictive maintenance of a reducer with contaminated oil under an excentrical load through vibration and oil analysis. J. Braz. Soc. Mech. Sci. Eng. 2011, 33, 1-7.

64. Hamilton, A.; Quail, F. Detailed state of the art review for the different on-line/in-line oil analysis techniques in context of wind turbine gearboxes. J. Tribol. 2011, 133, doi:10.1115/ 1.4004903 .

65. Walford, C.; Roberts, D. Condition Monitoring of Wind Turbines: Technology Overview, Seeded-Fault Testing, and Cost-Benefit Analysis; Technical Report 1010149; Global Energy Concepts, LLC: Kirkland, WA, USA, 2006.

66. Sheng, S.; Veers, P. Wind Turbine Drivetrain Condition Monitoring-An Overview; Mechanical Failures Prevention Group: Applied Systems Health Management Conference 2011, Virginia Beach, VA, USA, 10-12 May 2011.

67. Du, L.; Zhe, J. A high throughput inductive pulse sensor for online oil debris monitoring. Tribol. Int. 2011, 44, 175-179.

68. Hasan, I.; Rahaman, M.I. Intelligent Diagnostics and Predictive Maintenance Sensor System for Electrical Fault Diagnosis of Wind Turbine System. In Proceedings of the Global Engineering, Science and Technology Conference 2012, Dhaka, Bangladesh, 28-29 December 2012.

69. Park, J.-Y.; Lee, J.-K.; Oh, K.-Y.; Lee, J.-S.; Kim, B.-J. Design of Simulator for 3MW Wind Turbine and its Condition Monitoring System. In Proceedings of the International MultiConference of Engineers and Computer Scientists, IMECS 2010, Kowloon, Hong Kong, 17-19 March 2010; Volume II, pp. 930-933.

70. Jayaswal, P.; Wadhwani, A.; Mulchandani, K. Machine fault signature analysis. Int. J. Rotat. Mach. 2008, 2008, doi:10.1155/2008/583982.

71. Gong, X. Online Nonintrusive Condition Monitoring and Fault Detection for Wind Turbines. Ph.D. Thesis, Department of Electrical Engineering, University of Nebraska-Lincoln, Lincoln, NE, USA, August 2012.

72. Ciang, C.C.; Lee, J.-R.; Bang, H.-J. Structural health monitoring for a wind turbine system: A review of damage detection methods. Meas. Sci. Technol. 2008, 19, doi:10.1088/0957-0233/ 19/12/122001. 
73. Kreuzer, M. Strain Measurement with Fiber Bragg Grating Sensors; S2338-1.0 e; HBM GmbH: Darmstadt, Germany, 2006.

74. Bang, H.-J.; Kim, H.-I.; Lee, K.-S. Measurement of strain and bending deflection of a wind turbine tower using arrayed FBG sensors. Int. J. Precis. Eng. Manuf. 2012, 13, 2121-2126.

75. Lee, J.M.; Hwang, Y. A novel online rotor condition monitoring system using fiber Bragg grating (FBG) sensors and a rotary optical coupler. Meas. Sci. Technol. 2008, 19, doi:10.1088/ 0957-0233/19/6/065303.

76. Kang, L.-H.; Kim, D.-K.; Han, J.-H. Estimation of dynamic structural displacements using fiber Bragg grating strain sensors. J. Sound Vib. 2007, 305, 534-542.

77. Turner, A.; Graver, T.W. Structural monitoring of wind turbine blades using fiber optic Bragg grating strain sensors. Exp. Mech. Emerg. Energy Syst. Mater. 2011, 5, 149-154.

78. Schroeder, K.; Ecke, W.; Apitz, J.; Lembke, E.; Lenschow, G. A fibre Bragg grating sensor system monitors operational load in a wind turbine rotor blade. Meas. Sci. Technol. 2006, 17, doi:10.1088/0957-0233/17/5/S39.

79. Kramer, S.G.; Leon, F.P.; Appert, B. Fiber Optic Sensor Network for Lightning Impact Localization and Classification in Wind Turbines. In Proceedings of the 2006 IEEE International Conference on Multisensor Fusion and Integration for Intelligent Systems, Heidelberg, Germany, 3-6 September 2006; pp. 173-178.

80. Rademakers, L.W.M.M.; Vebruggen, T.W.; van der Werff, P.A.; Korterink, H.; Richon, D.; Rey, P.; Lancon, F. Fiber Optic Blade Monitoring. In Proceedings of the European Wind Energy Conference, London, UK, 22-25 November 2004; pp. 22-25.

81. Eum, S.; Kageyama, K.; Murayama, H.; Uzawa, K.; Ohsawa, I.; Kanai, M.; Igawa, H. Process/Health Monitoring for Wind Turbine Blade by Using FBG Sensors with Multiplexing Techniques. In Proceedings of the 19th International Society for Optics and Photonics, Perth, Australia, 14-18 April 2008; Volume 7004, doi:10.1117/12.786240.

82. Shin, C.; Chen, B.; Cheng, J.; Liaw, S. Impact response of a wind turbine blade measured by distributed FBG sensors. Mater. Manuf. Process. 2010, 25, 268-271.

83. Guemes, A.; Fernandez-Lopez, A.; Soller, B. Optical fiber distributed sensing-physical principles and applications. Struct. Health Monit. 2010, 9, 233-245.

84. Merzbacher, C.; Kersey, A.; Friebele, E. Fiber optic sensors in concrete structures: A review. Smart Mater. Struct. 1996, 5, doi:10.1088/0964-1726/5/2/008.

85. Moragues Pons, J. Practical Experiments on the Efficiency of the Remote Presence: Remote Inspection in an Offshore Wind Turbine. Master's Thesis, Norwegian University of Science and Technology, Trondheim, Norway, 21 June 2012.

86. Sheppard, R.; Puskar, F.; Waldhart, C. SS: Offshore Wind Energy Special Session: Inspection Guidance for Offshore Wind Turbine Facilities. In Proceedings of the Offshore Technology Conference, Houston, TA, USA, 3-6 May 2010.

87. Effren, D. Automated Turbine Inspection; AutoCopter ${ }^{\mathrm{TM}}$ Corporation: Charlotte, NC, USA, 2011.

88. Smarsly, K.; Law, K.H. Advanced Structural Health Monitoring Based on Multi-Agent Technology. In Computation for Humanity: Information Technology to Advance Society; Taylor \& Francis Group: Boca Raton, FL, USA, 2012. 
89. McGugan, M.; Larsen, G.C.; Sorensen, B.F.; Borum, K.K.; Engelhardt, J. Fundamentals for Remote Condition Monitoring of Offshore Wind Turbines; Danmarks Tekniske Universitet, Risø Nationallaboratoriet for Bæredygtig Energi: Risø, Denmark, 2008.

90. Balageas, D.; Fritzen, C.-P.; Güemes, A. Structural Health Monitoring; ISTE Ltd.: London, UK, 2006.

91. Schubel, P.; Crossley, R.; Boateng, E.; Hutchinson, J. Review of structural health and cure monitoring techniques for large wind turbine blades. Renew. Energy 2013, 51, 113-123.

92. Hyers, R.; McGowan, J.; Sullivan, K.; Manwell, J.; Syrett, B. Condition monitoring and prognosis of utility scale wind turbines. Energy Mater. 2006, 1, 187-203.

93. Watson, M.; Sheldon, J.; Amin, S.; Lee, H.; Byington, C.; Begin, M. A Comprehensive High Frequency Vibration Monitoring System for Incipient Fault Detection and Isolation of Gears, Bearings and Shafts/Couplings in Turbine Engines and Accessories. In Proceedings of the ASME Turbo Expo 2007: Power for Land, Sea, and Air, Montreal, QC, Canada, 14-17 May 2007; Volume 5, pp. 885-894.

94. Lading, L.; McGugan, M.; Sendrup, P.; Rheinlander, J.; Rusborg, J. Fundamentals for Remote Structural Health Monitoring of Wind Turbine Blades-A Preproject, Annex B: Sensors and Non-Destructive Testing Methods for Damage Detection in Wind Turbine Blades; Riso National Laboratory: Roskilde, Denmark, 2002.

95. Mba, D.; Rao, R.B. Development of acoustic emission technology for condition monitoring and diagnosis of rotating machines; bearings, pumps, gearboxes, engines and rotating structures. Shock Vib. Dig. 2006, 38, 3-16.

96. Tan, C.K.; Irving, P.; Mba, D. A comparative experimental study on the diagnostic and prognostic capabilities of acoustics emission, vibration and spectrometric oil analysis for spur gears. Mech. Syst. Signal Process. 2007, 21, 208-233.

97. Loutas, T.; Kalaitzoglou, J.; Sotiriades, G.; Kostopoulos, V. The Combined Use Of Vibration, Acoustic Emission And Oil Debris Sensor Monitored Data Coming From Rotating Machinery For The Development Of A Robust Health Monitoring System. Availble online: http://maritimeconferences.com/asranet2010-conference/asranet2008/53\%20Kostopoulos, \%20V.pdf (accessed on 22 February 2011).

98. Loutas, T.; Sotiriades, G.; Kalaitzoglou, I.; Kostopoulos, V. Condition monitoring of a single-stage gearbox with artificially induced gear cracks utilizing on-line vibration and acoustic emission measurements. Appl. Acoust. 2009, 70, 1148-1159.

99. Soua, S.; Lieshout, P.V.; Perera, A.; Gan, T.-H.; Bridge, B. Determination of the combined vibrational and acoustic emission signature of a wind turbine gearbox and generator shaft in service as a pre-requisite for effective condition monitoring. Renew. Energy 2013, 51, 175-181.

100. Raisutis, R.; Jasiuniene, E.; Sliteris, R.; Vladisauskas, A. The review of non-destructive testing techniques suitable for inspection of the wind turbine blades. Ultrasound 2008, 63, 26-30.

101. Rose, J.L. Ultrasonic guided waves in structural health monitoring. Key Eng. Mater. 2004, 270, $14-21$.

102. Lee, J.-R.; Takatsubo, J.; Toyama, N.; Kang, D.-H. Health monitoring of complex curved structures using an ultrasonic wavefield propagation imaging system. Meas. Sci. Technol. 2007, 18, doi:10.1088/0957-0233/18/12/017. 
103. Jasiuniene, E.; Raisutis, R.; Sliteris, R.; Voleisis, A.; Jakas, M. Ultrasonic NDT of wind turbine blades using contact pulse-echo immersion testing with moving water container. Ultrasound 2008, 63, 28-32.

104. Giurgiutiu, V.; Cuc, A. Embedded non-destructive evaluation for structural health monitoring, damage detection, and failure prevention. Shock Vib. Dig. 2005, 37, 83-105.

105. Tsai, C.-S.; Hsieh, C.-T.; Huang, S.-J. Enhancement of damage-detection of wind turbine blades via CWT-based approaches. IEEE Trans. Energy Convers. 2006, 21, 776-781.

106. Drewry, M.A.; Georgiou, G.A. A review of NDT techniques for wind turbines. Insight-Non-Destr. Test. Cond. Monit. 2007, 49, 137-141.

107. Cheng, L.; Tian, G.Y. Comparison of nondestructive testing methods on detection of delaminations in composites. J. Sens. 2012, 2012, doi:org/10.1155/2012/408437.

108. Jüngert, A. Damage Detection in Wind Turbine Blades Using Two Different Acoustic Techniques. In Proceedings of the 7th fib Ph.D. Symposium, Stuttgart, Germany, 11-13 September 2008.

109. Beattie, A.G.; Rumsey, M. Non-Destructive Evaluation of Wind Turbine Blades Using an Infrared Camera; SAND98-2824C; Sandia National Laboratory: Albuquerque, NM, USA, 1998.

110. Liu, W.; Tang, B.; Jiang, Y. Status and problems of wind turbine structural health monitoring techniques in China. Renew. Energy 2010, 35, 1414-1418.

111. Bodil, A.; Mats, D.; Magnus, U. Feasibility Study of Thermal Condition Monitoring and Condition Based Maintenance in Wind Turbines; Elforsk Report 11:19; ELFORSK: Stockholm, Sweden, 2011.

112. Ge, Z.; Du, X.; Yang, L.; Yang, Y.; Li, Y.; Jin, Y. Performance monitoring of direct air-cooled power generating unit with infrared thermography. Appl. Therm. Eng. 2011, 31, 418-424.

113. Yang, W.; Tavner, P.J.; Crabtree, C.J.; Wilkinson, M. Cost-effective condition monitoring for wind turbines. IEEE Trans. Ind. Electron. 2010, 57, 263-271.

114. Yang, W.; Jiang, J.; Tavner, P.; Crabtree, C. Monitoring Wind Turbine Condition by the Approach of Empirical Mode Decomposition. In Proceedings of the International Conference on Electrical Machines and Systems, ICEMS 2008, Wuhan, Hubei, China, 17-20 October 2008; pp. 736-740.

115. Yang, W.; Tavner, P.; Crabtree, C.; Wilkinson, M. Research on a Simple, Cheap but Globally Effective Condition Monitoring Technique for Wind Turbines. In Proceedings of the 18th International Conference on Electrical Machines, ICEM 2008, Vilamoura, Portugal, 6-9 September 2008; pp. 1-5.

116. Wilkinson, M.R.; Spinato, F.; Tavner, P.J. Condition Monitoring of Generators \& Other Subassemblies in Wind Turbine Drive Trains. In Proceedings of the IEEE International Symposium on Diagnostics for Electric Machines, Power Electronics and Drives, SDEMPED 2007, Cracow, Poland, 6-8 September 2007; pp. 388-392.

117. Costinas, S.; Diaconescu, I.; Fagarasanu, I. Wind Power Plant Condition Monitoring. In Proceedings of the 3rd WSEAS International Conference on Energy Planning, Energy Saving, Environmental Education (EPESE '09), Canary Islands, Spain, 1-3 July 2009; pp. 71-76.

118. Fuchs, E.; Masoum, M.A.S. Power Quality in Power Systems and Electrical Machines; Elsevier Academic Press: Burlington, MA, USA, 2008. 
119. Yang, W.; Tavner, P.J.; Crabtree, C.J. An Intelligent Approach to the Condition Monitoring of Large Scale Wind Turbines. In Proceedings of the European Wind Energy Conference and Exhibition (EWEC2009), Marseille, France, 16-19 March 2009.

120. Cook, K. A Power Quality Monitoring System for a $20 \mathrm{~kW}$ Ocean Turbine. Master's Thesis, Florida Atlantic University, Dania Beach, FL, USA, August 2010.

121. Qiao, W. Recovery Act: Online Nonintrusive Condition Monitoring and Fault Detection for Wind Turbines; Award Number DE-EE0001366; University of Nebraska-Lincoln, Lincoln, NE, USA, 2012.

122. Watson, S.J.; Xiang, B.J.; Yang, W.; Tavner, P.J.; Crabtree, C.J. Condition monitoring of the power output of wind turbine generators using wavelets. IEEE Trans. Energy Convers. 2010, 25, $715-721$.

123. Amirat, Y.; Choqueuse, V.; Benbouzid, M. Condition Monitoring of Wind Turbines Based on Amplitude Demodulation. In Proceedings of the 2010 IEEE Energy Conversion Congress and Exposition (ECCE), Atlanta, GA, USA, 12-16 September 2010; pp. 2417-2421.

124. Wakui, T.; Yokoyama, R. Wind speed sensorless performance monitoring based on operating behavior for stand-alone vertical axis wind turbine. Renew. Energy 2013, 53, 49-59.

125. Yang, W.X.; Tavner, P.J.; Crabtree, C.J. Bivariate empirical mode decomposition and its contribution to wind turbine condition monitoring. J. Sound Vib. 2011, 330, 3766-3782.

126. Yang, W.X.; Tavner, P.J.; Court, R. An online technique for condition monitoring the induction generators used in wind and marine turbines. Mech. Syst. Signal Process. 2012, 38, 103-112.

127. Gill, S.; Stephen, B.; Galloway, S. Wind turbine condition assessment through power curve copula modeling. IEEE Trans. Sustain. Energy 2012, 3, 94-101.

128. Yazidi, A.; Henao, H.; Capolino, G.; Artioli, M.; Filippetti, F.; Casadei, D. Flux Signature Analysis: An Alternative Method for the Fault Diagnosis of Induction Machines. In Proceedings of the 2005 IEEE Russia Power Tech, St. Petersburg, Russia, 27-30 June 2005; pp. 1-6.

129. Yazidi, A.; Capolino, G.; Filippetti, F.; Casadei, D. A New Monitoring System for Wind Turbines with Doubly-Fed Induction Generators. In Proceedings of the IEEE Mediterranean Electrotechnical Conference, MELECON 2006, Malaga, Spain, 16-19 May 2006; pp. 1142-1145.

130. Douglas, H.; Pillay, P.; Barendse, P. The Detection of Interturn Stator Faults in Doubly-Fed Induction Generators. In Proceedings of the Conference Record of the 2005 Industry Applications Conference, Fourtieth IAS Annual Meeting, Kowloon, Hong Kong, 2-6 October 2005; Volume 2, pp. 1097-1102.

131. Yang, W.; Tavner, P.; Wilkinson, M. Wind Turbine Condition Monitoring and Fault Diagnosis Using Both Mechanical and Electrical Signatures. In Proceedings of the IEEE/ASME International Conference on Advanced Intelligent Mechatronics, AIM 2008, Xian, Shannxi, China, 2-5 July 2008; pp. 1296-1301.

132. Butler, S.; O’Connor, F.; Farren, D.; Ringwood, J.V. A Feasibility Study into Prognostics for the Main Bearing of A Wind Turbine. In Proceedings of the 2012 IEEE International Conference on Control Applications (CCA), Dubrovnik, Croatia, 3-5 October 2012; pp. 1092-1097.

133. Chen, B. Survey of Commercially Available SCADA Data Analysis Tools for Wind Turbine Health Monitoring; School of Engineering and Computing Sciences, Durham University: Durham, UK, 2010. 
134. Schlechtingen, M.; Santos, I.F. Condition Monitoring with Ordinary Wind Turbine SCADA Data-A Neuro-Fuzzy Approach. In Proceedings of the European Wind Energy Association (EWEA) Offshore 2011, Amsterdam, The Netherlands, 29 November-1 December 2011.

135. Schlechtingen, M.; Santos, I.F.; Achiche, S. Wind turbine condition monitoring based on SCADA data using normal behavior models: Part 1: System description. Appl. Soft Comput. 2013, 13, 259-270.

136. Li, H.; Hu, Y.; Yang, C.; Chen, Z.; Ji, H.; Zhao, B. An improved fuzzy synthetic condition assessment of a wind turbine generator system. Int. J. Electr. Power Energy Syst. 2013, 45, 468-476.

137. Yang, W.X.; Court, R.; Jiang, J.S. Wind turbine condition monitoring by the approach of SCADA data analysis. Renew. Energy 2013, 53, 365-376.

138. Crabtree, C.J. Survey of Commercially Available Condition Monitoring Systems for Wind Turbines; Durham University: Durham, UK, 2010.

139. Wang, W. An intelligent system for machinery condition monitoring. IEEE Trans. Fuzzy Syst. 2008, 16, 110-122.

140. Amirat, Y.; Choqueuse, V.; Benbouzid, M. Wind Turbines Condition Monitoring and Fault Diagnosis Using Generator Current Amplitude Demodulation. In Proceedings of the 2010 IEEE International Energy Conference and Exhibition (EnergyCon), Manama, Bahrain, 18-22 December 2010; pp. 310-315.

141. Zimroz, R.; Urbanek, J.; Barszcz, T.; Bartelmus, W.; Millioz, F.; Martin, N. Measurement of instantaneous shaft speed by advanced vibration signal processing-application to wind turbine gearbox. Metrol. Meas. Syst. 2011, 18, 701-712.

142. Ye, X.; Yan, Y.; Osadciw, L.A. Learning Decision Rules by Particle Swarm Optimization (PSO) for Wind Turbine Fault Diagnosis. In Proceedings of the Annual Conference of the Prognostics and Health Management Society 2010, Portland, OR, USA, 10-16 October 2010.

143. Boyle, D.; Magno, M.; O’Flynn, B.; Brunelli, D.; Popovici, E.; Benini, L. Towards Persistent Structural Health Monitoring through Sustainable Wireless Sensor Networks. In Proceedings of the 2011 Seventh International Conference on Intelligent Sensors, Sensor Networks and Information Processing (ISSNIP), Adelaide, SA, Australia, 6-9 December 2011; pp. 323-328.

144. Christensen, J.J.; Andersson, C.; Gutt, S. Remote Condition Monitoring of Vestas Turbines. In Proceedings of the of European Wind Energy Conference and Exhibition (EWEC2009), Marseille, France, 16-19 March 2009.

145. Miguelanez, E.; Lane, D. Predictive Diagnosis for Offshore Wind Turbines Using Holistic Condition Monitoring. In Proceedings of the OCEANS 2010, Seattle, WA, USA, 20-23 September 2010; pp. 1-7.

146. Higgs, P.A.; Parkin, R.; Jackson, M.; Al-Habaibeh, A.; Zorriassatine, F.; Coy, J. A Survey on Condition Monitoring Systems in Industry. In Proceedings of the ASME 7th Biennial Conference on Engineering Systems Design and Analysis, Manchester, UK, 19-22 July 2004; Volume 3, pp. 163-178.

147. Yang, B.; Sun, D. Testing, inspecting and monitoring technologies for wind turbine blades: A survey. Renew. Sustain. Energy Rev. 2013, 22, 515-526. 
148. Lynch, J.P.; Loh, K.J. A summary review of wireless sensors and sensor networks for structural health monitoring. Shock Vib. Dig. 2006, 38, 91-130.

149. Smarsly, K.; Law, K.H.; Hartmann, D. Implementing a Multiagent-Based Self-Managing Structural Health Monitoring System on a Wind Turbine. In Proceedings of the 2011 NSF Engineering Research and Innovation Conference, Atlanta, GA, USA, 4-7 January 2011.

150. Diamanti, K.; Soutis, C. Structural health monitoring techniques for aircraft composite structures. Prog. Aerosp. Sci. 2010, 46, 342-352.

151. Giurgiutiu, V.; Zagrai, A.; Bao, J.J. Piezoelectric wafer embedded active sensors for aging aircraft structural health monitoring. Struct. Health Monit. 2002, 1, 41-61.

152. Seah, W.K.; Eu, Z.A.; Tan, H.-P. Wireless Sensor Networks Powered by Ambient Energy Harvesting (WSN-HEAP)-Survey and Challenges. In Proceedings of the 1st International Conference on Wireless Communication, Vehicular Technology, Information Theory and Aerospace \& Electronic Systems Technology, Wireless VITAE 2009, Aalborg, Denmark, 17-20 May 2009; pp. 1-5.

153. Eu, Z.A.; Tan, H.-P.; Seah, W.K. Design and performance analysis of MAC schemes for wireless sensor networks powered by ambient energy harvesting. Ad Hoc Netw. 2011, 9, 300-323.

154. Fu, T.S.; Ghosh, A.; Johnson, E.A.; Krishnamachari, B. Energy-efficient deployment strategies in structural health monitoring using wireless sensor networks. Struct. Control Health Monit. 2013, 20, 971-986.

155. Park, G.; Rosing, T.; Todd, M.D.; Farrar, C.R.; Hodgkiss, W. Energy harvesting for structural health monitoring sensor networks. J. Infrastruct. Syst. 2008, 14, 64-79.

156. Ling, Q.; Tian, Z.; Yin, Y.; Li, Y. Localized structural health monitoring using energy-efficient wireless sensor networks. IEEE Sens. J. 2009, 9, 1596-1604.

157. Daliri, A.; Galehdar, A.; Rowe, W.S.; Ghorbani, K.; John, S. Utilising microstrip patch antenna strain sensors for structural health monitoring. J. Intell. Mater. Syst. Struct. 2012, 23, 169-182.

158. Daliri, A.; Galehdar, A.; John, S.; Rowe, W.; Ghorbani, K. Circular Microstrip Patch Antenna Strain Sensor for Wireless Structural Health Monitoring. In Proceedings of the World Congress on Engineering, WCE 2010, London, UK, 30 June-2 July 2010; Volume II, pp. 1173-1178.

159. Daliri, A.; Galehdar, A.; John, S.; Rowe, W.S.T.; Ghorbani, K. Slotted Circular Microstrip Patch Antenna Application in Strain Based Structural Health Monitoring. In Proceedings of the AIAC14 Fourteenth Australian International Aerospace Congress, Melbourne, Australia, 28 February-3 March 2011.

160. Taylor, S.G.; Farinholt, K.M.; Flynn, E.B.; Figueiredo, E.; Mascarenas, D.L.; Moro, E.A.; Park, G.; Todd, M.D.; Farrar, C.R. A mobile-agent-based wireless sensing network for structural monitoring applications. Meas. Sci. Technol. 2009, 20, doi:10.1088/0957-0233/20/4/045201.

161. Park, J.-Y.; Kim, B.-J.; Lee, J.-K. Development of Condition Monitoring System with Control Functions for Wind Turbines. World Acad. Sci. Eng. Technol. 2011, 5, 269-274.

162. Isko, V.; Mykhaylyshyn, V.; Moroz, I.; Ivanchenko, O.; Rasmussen, P. Remote Wind Turbine Generator Condition Monitoring with Mita-Teknik's WP4086 System. In Proceedings of the 2010 European Wind Energy Conference (EWEC) \& Exhibition, Warsaw, Poland, 20-23 April 2010.

163. Koutroulis, E.; Kalaitzakis, K. Development of an integrated data-acquisition system for renewable energy sources systems monitoring. Renew. Energy 2003, 28, 139-152. 
164. Feuchtwang, J.; Infield, D. The Offshore Access Problem and Turbine Availability-Probabilistic Modelling of Expected Delays to Repairs. In Procedings of the European Offshore Wind (EOW) Conference \& Exhibition, Stockholm, Sweden, 14-16 September 2009.

165. Karyotakis, A. On the Optimisation of Operation and Maintenance Strategies for Offshore Wind Farms. Ph.D. Thesis, University College London (UCL), London, UK, 2011.

166. Byon, E.; Ding, Y. Season-dependent condition-based maintenance for a wind turbine using a partially observed Markov decision process. IEEE Trans. Power Syst. 2010, 25, 1823-1834.

167. Jensen, F.M.; Falzon, B.; Ankersen, J.; Stang, H. Structural testing and numerical simulation of a 34 m composite wind turbine blade. Compos. Struct. 2006, 76, 52-61.

(C) 2014 by the authors; licensee MDPI, Basel, Switzerland. This article is an open access article distributed under the terms and conditions of the Creative Commons Attribution license (http://creativecommons.org/licenses/by/3.0/). 